\title{
¿Surface Fluxes Modulate the Seasonality of Zonal-Mean Storm Tracks
}

\author{
Pragallva BARPANDA AND Tiffany A. SHAW \\ Department of the Geophysical Sciences, University of Chicago, Chicago, Illinois
}

(Manuscript received 20 May 2019, in final form 19 November 2019)

\begin{abstract}
The observed zonal-mean extratropical storm tracks exhibit distinct hemispheric seasonality. Previously, the moist static energy (MSE) framework was used diagnostically to show that shortwave absorption (insolation) dominates seasonality but surface heat fluxes damp seasonality in the Southern Hemisphere (SH) and amplify it in the Northern Hemisphere (NH). Here we establish the causal role of surface fluxes (ocean energy storage) by varying the mixed layer depth $d$ in zonally symmetric 1 ) slab-ocean aquaplanet simulations with zero ocean energy transport and 2) energy balance model (EBM) simulations. Using a scaling analysis we define a critical mixed layer depth $d_{c}$ and hypothesize 1) large mixed layer depths $\left(d>d_{c}\right)$ produce surface heat fluxes that are out of phase with shortwave absorption resulting in small storm track seasonality and 2) small mixed layer depths $\left(d<d_{c}\right)$ produce surface heat fluxes that are in phase with shortwave absorption resulting in large storm track seasonality. The aquaplanet simulations confirm the large mixed layer depth hypothesis and yield a useful idealization of the SH storm track. However, the small mixed layer depth hypothesis fails to account for the large contribution of the Ferrel cell and atmospheric storage. The small mixed layer limit does not yield a useful idealization of the NH storm track because the seasonality of the Ferrel cell contribution is opposite to the stationary eddy contribution in the NH. Varying the mixed layer depth in an EBM qualitatively supports the aquaplanet results.
\end{abstract}

\section{Introduction}

The zonal-mean extratropical storm tracks exhibit distinct hemispheric seasonality. In the Northern Hemisphere $(\mathrm{NH})$ the storm track weakens by $\sim 2.5 \mathrm{PW}$ and shifts poleward by $\sim 10^{\circ}$ from winter to summer. The Southern Hemisphere $(\mathrm{SH})$ storm track shows much smaller seasonality $\left(<1 \mathrm{PW}\right.$ intensity change and $<3^{\circ}$ shift; Chang et al. 2002; Shaw et al. 2016). Overall, stormtrack seasonality is much larger than changes due to global warming or interannual variability (O'Gorman 2010; Barpanda and Shaw 2017, hereafter B17; Shaw et al. 2018, hereafter S18).

Several frameworks have been used to diagnose the factors affecting zonal-mean storm track seasonality. The first group focuses on the seasonality of time- and zonal-mean temperature. For example, the Eady parameter, which peaks where baroclinicity is largest, has been used to explain storm track seasonality excluding

¿ Denotes content that is immediately available upon publication as open access.

Corresponding author: Tiffany A. Shaw, tas1@uchicago.edu the midwinter minimum (Nakamura 1992; Chang et al. 2002). In addition, Kushner and Held (1998) showed that the seasonality of the storm tracks in the lower troposphere follow a downgradient diffusive model; that is, they follow the seasonality of the time-mean temperature gradient. Finally, O'Gorman (2010) showed that the seasonality of zonal-mean storm track intensity follows mean available potential energy (MAPE). MAPE is related to the vertical and meridional structure of the zonal- and time-mean temperature and is proportional to the square of the Eady growth rate (O'Gorman and Schneider 2008).

The second group focuses on moist static energy (MSE). Recently, B17 and S18 developed a framework for zonal-mean storm track position and intensity based on the MSE budget. It provides a clear connection between storm tracks and seasonal insolation. In particular, storm track position and intensity are related to net energy input (top-of-atmosphere radiation minus surface fluxes and atmospheric storage) and MSE transport by the stationary circulation (mean meridional circulation and stationary eddies). B17 and S18 showed that the MSE framework could be used to test the hypothesis that top-of-atmosphere (TOA) insolation controls storm track seasonality. The test revealed insolation 
controls the phase of storm track seasonality but not the amplitude. The MSE framework was subsequently used diagnostically to show shortwave absorption (TOA minus surface shortwave) dominates the seasonality of storm track intensity and the factor accounting for the hemispheric difference was surface heat fluxes (turbulent surface latent and sensible heat flux plus surface longwave radiation), which are part of the net energy input. Surface heat fluxes are out of phase with shortwave absorption in the SH leading to small seasonal intensity whereas surface heat fluxes are in phase with shortwave absorption in the $\mathrm{NH}$ leading to large seasonal intensity. According to the MSE framework, the dominant factor accounting for hemispheric differences in seasonal position is the stationary eddy MSE flux, which offsets the equator-to-pole energy imbalance implied from the net energy input.

It is difficult to interpret the results mentioned above for several reasons. First, the seasonal mean temperaturestorm track relationship is not causal because storm tracks' feedback on the mean temperature structure (Hoskins and Valdes 1990; Shaw et al. 2016). Second, storm tracks interact with components of the MSE framework: storm tracks produce clouds, which impact the cloud radiative effect (Ceppi and Hartmann 2015), storm tracks affect the amplitude of stationary eddies (Held et al. 2002) and eddy momentum fluxes drive the Ferrel cell (Schneider 2006). Nevertheless, the MSE framework is appealing because it includes external control parameters, for example, insolation and surface albedo. These parameters can form the basis of predictions as shown by B17 and S18. Unfortunately, frameworks based on mean temperature cannot be easily related to external parameters, such as insolation, which is the main driver of storm track seasonality.

Here we hypothesize that surface fluxes (surface shortwave radiation minus surface heat fluxes) modulate the seasonality of zonal-mean storm tracks. We focus on surface fluxes because 1) they can be controlled by an external parameter (the mixed layer depth) in slab-ocean aquaplanet models and in energy balance models (EBMs) and 2) they affect the seasonality of surface heat fluxes, which S18 showed was important for the hemispheric difference in seasonal storm track intensity. We are also motivated by previous work that demonstrated the impact of mixed layer depth on the zonally symmetric slab-ocean aquaplanet climate. In particular, aquaplanet simulations with a $50 \mathrm{~m}$ mixed layer depth capture the seasonality of atmospheric temperature in the $\mathrm{SH}$, which is mostly ocean and therefore has a large effective heat capacity (Donohoe et al. 2014). Whereas aquaplanet simulations with a $1 \mathrm{~m}$ mixed layer depth capture the seasonality of the Asian monsoon in the $\mathrm{NH}$, which has more land and therefore a small effective heat capacity (Bordoni and Schneider 2008).
We test our hypothesis by varying the mixed layer depth in zonally symmetric slab-ocean aquaplanet simulations without ocean energy transport. In addition, we vary the mixed layer depth in an EBM to understand connections to storm track frameworks based on mean surface temperature. We focus on zonally symmetric storm tracks as a first step in understanding the different hemispheric seasonality of zonal-mean storm tracks on Earth. While the $\mathrm{NH}$ storm track is clearly influenced by stationary eddies, zonally symmetric dynamics may still be useful if the impact of stationary circulations that are present on Earth are similar to the zonal-mean meridional circulation in the zonally symmetric aquaplanet.

The paper is organized as follows. We review the MSE framework and outline our hypotheses in section 2. We describe the details of the aquaplanet and EBM simulations in section 3. In section 4, we test our hypotheses using the aquaplanet simulations, fully diagnose storm track seasonality using the MSE framework and relate the aquaplanet results to the observed storm tracks. We also examine the response of the EBM to changes in mixed layer depth, including its impact on mean surface temperature. The conclusions and discussion are summarized in section 5 .

\section{Energetic framework and hypotheses}

B17 and S18 derived an energetic framework for storm track position and intensity based on the atmospheric MSE budget:

$$
F_{\mathrm{MM}}+F_{\mathrm{SE}}+F_{\mathrm{TE}}=\left(\overline{\left[F_{\mathrm{EIA}}\right]}\right)-\partial_{t}\langle\overline{[h]}\rangle \equiv F_{\mathrm{NE}},
$$

where $F_{\mathrm{MM}}=\partial_{y}\langle[\bar{v}][\bar{m}]\rangle, F_{\mathrm{SE}}=\partial_{y}\left\langle\left[\bar{v}^{*} \bar{m}^{*}\right]\right\rangle$, and $F_{\mathrm{TE}}=$ $\partial_{y}\left\langle\left[\overline{v^{\prime} m^{\prime}}\right]\right\rangle$ are the MSE flux divergence by the mean meridional circulation, stationary and transient eddies; $v$ is meridional wind; $m$ is $\operatorname{MSE}\left(m=c_{p} T+L q+\Phi\right)$, where $c_{p}$ is specific heat of air at constant pressure, $T$ is temperature, $L$ is the latent heat of vaporization, $q$ is specific humidity, and $\Phi$ is geopotential; the overbar and square brackets denote monthly and zonal averages, respectively, with the prime and the asterisk representing deviations from those averages, respectively; angle brackets denote mass-weighted vertical integration; $\partial_{y}(\cdot) \equiv \partial_{\phi}[\cos \phi(\cdot)] / a \cos \phi$ is the meridional divergence in spherical coordinates, where $\phi$ is latitude and $a$ is the radius of Earth; $t$ is time; and $h$ is the thermal energy $\left(h=c_{p} T+L q\right)$. The net energy input $F_{\mathrm{NE}}$ is the difference between energy input to the atmosphere $\left[F_{\mathrm{EIA}}=\right.$ $\left.F_{\mathrm{TOA}}-F_{\mathrm{SFC}}\right]$ and atmospheric storage $\partial_{t}\langle\overline{[h]}\rangle$; that is, $F_{\mathrm{NE}}=F_{\mathrm{TOA}}-F_{\mathrm{SFC}}-\partial_{t}\langle\overline{[h]}\rangle$, where $F_{\mathrm{TOA}}$ is TOA radiation and $F_{\mathrm{SFC}}$ is surface fluxes. The net energy input can 
be further decomposed following Donohoe and Battisti (2013); that is,

$$
F_{\mathrm{NE}}=F_{\mathrm{SWABS}}+F_{\mathrm{SHF}}-F_{\mathrm{OLR}}-\partial_{t}\langle\overline{[h]}\rangle,
$$

where $F_{\text {SWABS }}$ is shortwave absorption in the atmosphere (TOA minus surface shortwave radiation), $F_{\mathrm{SHF}}$ is surface heat flux (surface longwave radiation plus turbulent surface latent and sensible heat fluxes) and $F_{\text {OLR }}$ is outgoing longwave radiation (OLR).

The storm track position $\phi_{s}$ is identified as the latitude where the transient eddy MSE flux divergence is zero; that is, $\left.F_{\mathrm{TE}}\right|_{\phi_{s}}=0$. The storm track intensity $I$ is the value of zonal-mean transient eddy MSE flux at the storm track position; that is, $I=\left.2 \pi a \cos \phi_{s}\left\langle\overline{\left[v^{\prime} m^{\prime}\right]}\right\rangle\right|_{\phi_{s}}$. Note that storm track intensity is negative in the $\mathrm{SH}$ and thus $\Delta I>0$ indicates a weakening of the $\mathrm{SH}$ storm track. S18 showed that defining storm tracks using a monthly average produced similar results to defining them using a 10-day high-pass filter (see appendix A of S18). We find similar agreement in our aquaplanet simulations (see appendix A, Figs. A1 and A2).

According to the MSE framework, a change in storm track intensity $\Delta I$ is decomposed into contributions from net energy input integrated poleward of the storm track and MSE fluxes by the mean meridional circulation and stationary eddies at the storm track position:

$$
\Delta I=\Delta I_{\mathrm{NE}}-\Delta I_{\mathrm{MM}}-\Delta I_{\mathrm{SE}},
$$

where $I_{\mathrm{NE}}=2 \pi a^{2} \cos \phi \int_{\pi / 2}^{\phi_{s}} \cos \phi F_{\mathrm{NE}} d \phi, I_{\mathrm{MM}}=2 \pi a \cos \phi_{s}$ $\left.\langle[\bar{v}][\bar{m}]\rangle\right|_{\phi_{s}}$, and $I_{\mathrm{SE}}=\left.2 \pi a \cos \phi_{s}\left\langle\left[\bar{v}^{*} \bar{m}^{*}\right]\right\rangle\right|_{\phi_{s}}$ (S18, section 2, for details). Similarly, a change in storm track position $\Delta \phi$ is decomposed into contributions from net energy input $\Delta \phi_{\mathrm{NE}}$, mean meridional circulation $\Delta \phi_{\mathrm{MM}}$, stationary eddies $\Delta \phi_{\mathrm{SE}}$, and a cross term $\Delta \phi_{\mathrm{CT}}$ :

$$
\Delta \phi=\Delta \phi_{\mathrm{NE}}+\Delta \phi_{\mathrm{MM}}+\Delta \phi_{\mathrm{SE}}+\Delta \phi_{\mathrm{CT}},
$$

where $\Delta \phi_{\mathrm{CT}}$ arises from nonlinearities (see B17, section 2, method 2, for details).

To illustrate a diagnostic application of the MSE framework, we quantify the seasonal evolution of storm track intensity as an anomaly relative to the annual mean for 2000-15. (Note that this seasonal analysis is different from S18 who quantified month-to-month seasonality.) Following S18, we combine Clouds and the Earth's Radiant Energy System (CERES) Energy Balanced and Filled (EBAF) radiation (TOA longwave, shortwave, and surface shortwave) data with MSE flux and atmospheric storage data from ERA-Interim. The surface heat flux is calculated as a residual of the MSE budget in (1). Following S18, when computing the contributions to $I_{\mathrm{NE}}$ the global mean is subtracted prior to computing the spatial integral over the polar cap to ensure the implied energy transport at $\phi_{s}$ is independent of whether the integral is computed from the South Pole to $\phi_{s}$ or the North Pole to $\phi_{s}$. In addition, the reanalysis uncertainty is defined as the difference between ERA-Interim and NCEP over the $2000-15$ period and is $\sim 0.3 \mathrm{PW}$.

According to the MSE framework, the seasonality of SH storm track intensity is negligible and follows the evolution of net energy input (cf. red and magenta lines, Fig. 1a). The seasonality of NH storm track intensity is large and mostly follows the evolution of net energy input (cf. red and magenta lines, Fig. 1b). Stationary eddies contribute to a midwinter minimum in the $\mathrm{NH}$ (blue line, Fig. 1b). Therefore, from a zonally symmetric perspective, the different hemispheric seasonality of storm track intensity is connected to the seasonality of net energy input. Decomposing the net energy input following (2) shows that shortwave absorption (insolation) dominates seasonality in both hemispheres (orange line, Figs. 1c,d). In the SH, the seasonality of net energy input is negligible because surface heat fluxes are out of phase with shortwave absorption along with OLR and atmospheric storage (Fig. 1c). In contrast, in the $\mathrm{NH}$ the seasonality of net energy input is large because surface heat fluxes are in phase with shortwave absorption (Fig. 1d). Thus, the different hemispheric seasonality of storm track intensity is dominated by the different seasonality of surface heat fluxes. Shortwave absorption is also somewhat different between the hemispheres, but it is not important throughout the seasonal cycle. OLR and atmospheric storage do not exhibit hemispheric differences larger than reanalysis uncertainty.

To build a causal understanding of surface heat fluxes for storm track seasonality we focus on surface fluxes. Surface fluxes and surface heat fluxes are connected via the surface energy budget:

$$
F_{\mathrm{SFC}}=F_{\mathrm{SW}_{\mathrm{scc}}}-F_{\mathrm{SHF}}=d \rho_{o} c_{p_{o}} \frac{\partial T_{s}}{\partial t}+\nabla \cdot \mathbf{F}_{o},
$$

where $F_{\mathrm{SW}_{\text {sf }}}$ is surface shortwave radiation, $d$ is mixed layer depth of the ocean, $\rho_{o}$ is density of water, $c_{p_{o}}$ is specific heat capacity of water, $T_{s}$ is sea surface temperature (SST), and $\nabla \cdot \mathbf{F}_{o}$ is the ocean energy flux convergence. If ocean energy transport $\mathbf{F}_{o}$ is negligible (a reasonable assumption for the extratropics and seasonal time scale; see Figs. $4 \mathrm{c}$ and $5 \mathrm{c}$ in Roberts et al. 2017), then the mixed layer depth controls surface fluxes.

Assuming the stationary circulation and atmospheric storage contributions are negligible, we hypothesize the mixed layer depth (surface fluxes) modulates storm track seasonality as follows: 
(a)

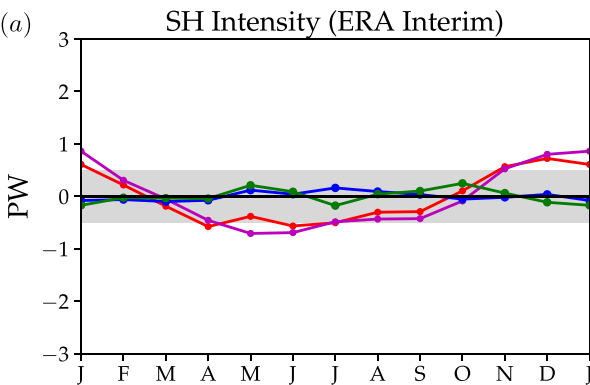

(c)

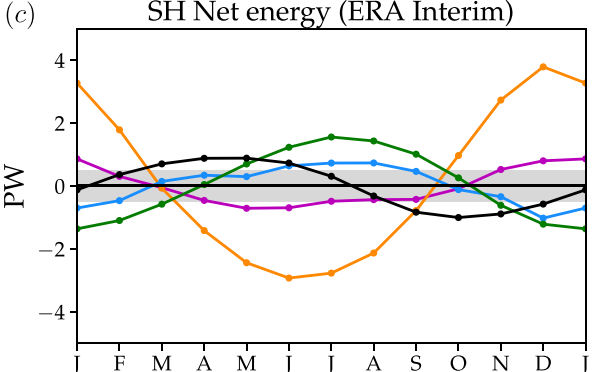

(b)

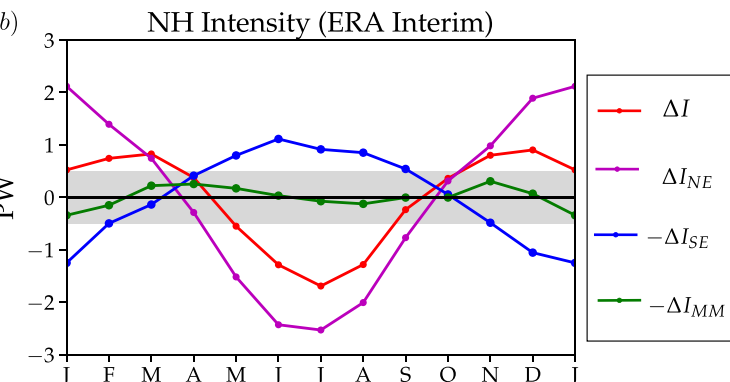

$(d)$

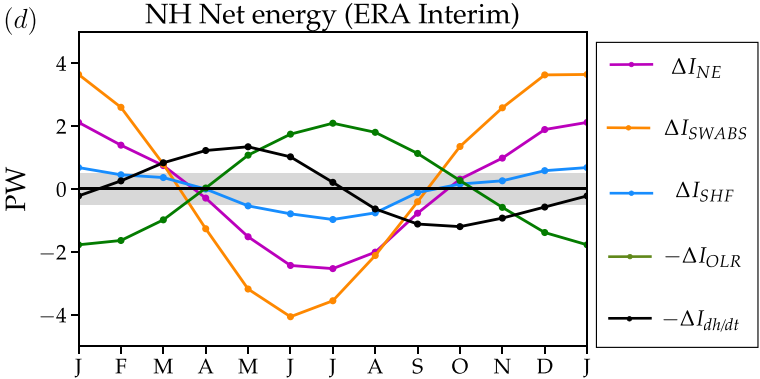

FIG. 1. (a),(b) Decomposition of storm track intensity as an anomaly relative to the annual-mean $\Delta I$ into contributions from net energy input $\Delta I_{\mathrm{NE}}$, stationary eddies $\Delta I_{\mathrm{SE}}$, and mean meridional circulation $\Delta I_{\mathrm{MM}}$. (c),(d) Decomposition of net energy input $\Delta I_{\mathrm{NE}}$ contribution to storm track intensity anomaly into atmospheric shortwave absorption $\Delta I_{\text {SWABS }}$, surface heat flux $\Delta I_{\mathrm{SHF}}$, outgoing longwave radiation $\Delta I_{\mathrm{OLR}}$, and atmospheric storage $\Delta I_{d h / d t}$. (left) $\mathrm{SH}$ and (right) $\mathrm{NH}$ for ERA-Interim.

1) If the mixed layer depth is large then surface fluxes become large enough to compensate TOA radiation, that is, $\Delta F_{\mathrm{SFC}} \approx \Delta F_{\mathrm{TOA}}$, the seasonality of net energy input is small, shortwave absorption is out of phase with surface heat fluxes, and storm track seasonality is small.

2) If the mixed layer depth is small then surface fluxes are small, that is, $\Delta F_{\mathrm{SFC}}<\Delta F_{\mathrm{TOA}}$, the seasonality of net energy input is large, shortwave absorption is in phase with surface heat fluxes, and storm track seasonality is large.

The phase relationships between shortwave absorption and surface heat fluxes were deduced as follows. If the mixed layer depth is large, then

$$
\begin{aligned}
\Delta F_{\mathrm{SFC}} \approx \Delta F_{\mathrm{TOA}} & \Rightarrow \Delta F_{\mathrm{TOA}} \approx F_{\mathrm{SW}_{\mathrm{scc}}}-\Delta F_{\mathrm{SHF}} \\
& \Rightarrow \Delta F_{\mathrm{SWABS}}-\Delta F_{\mathrm{OLR}} \approx-\Delta F_{\mathrm{SHF}} \\
& \Rightarrow \Delta F_{\mathrm{SWABS}} \approx-\Delta F_{\mathrm{SHF}},
\end{aligned}
$$

assuming shortwave absorption dominates over OLR. If the mixed layer depth is small, then

$$
\begin{aligned}
\Delta F_{\mathrm{SFC}} \approx 0 & \Rightarrow \Delta F_{\mathrm{SW}, \mathrm{Sfc}}-\Delta F_{\mathrm{SHF}} \approx 0 \\
& \Rightarrow \Delta F_{\mathrm{SW}, \mathrm{scc}} \approx \Delta F_{\mathrm{SHF}} \\
& \Rightarrow \Delta F_{\mathrm{SWABS}} \approx \Delta F_{\mathrm{SHF}},
\end{aligned}
$$

assuming surface shortwave radiation is in phase with shortwave absorption.

The different mixed layer depth limits are relative to a critical depth, which we estimate using a scaling analysis of the MSE budget that assumes TOA insolation and surface fluxes are the same order of magnitude; that is,

$$
d_{c} \approx \frac{(1-\alpha) S_{0} T}{\rho_{o} c_{p_{o}} T_{s}} \approx 10 \mathrm{~m}
$$

where $\alpha=0.3$ is the planetary albedo, $S_{0}=500 \mathrm{~W} \mathrm{~m}^{-2}$ is the maximum insolation in the extratropics, $T_{s}=300 \mathrm{~K}$ and $T=1$ year. Here we follow the scaling conventions in Vallis (2006).

\section{Model simulations}

\section{a. Aquaplanet}

We perform zonally symmetric slab-ocean aquaplanet simulations using two different general circulation models (GCMs): 1) Isca (Vallis et al. 2018) and 2) Geophysical Fluid Dynamics Laboratory (GFDL) Atmospheric Model 2.1 (Anderson et al. 2004; Delworth et al. 2006). The Isca simulations use clear-sky RRTMG radiation (Mlawer et al. 1997), the Betts-Miller convection scheme (Betts and Miller 1993) and are configured with spectral T42 resolution and 40 unevenly spaced sigma levels. A constant 

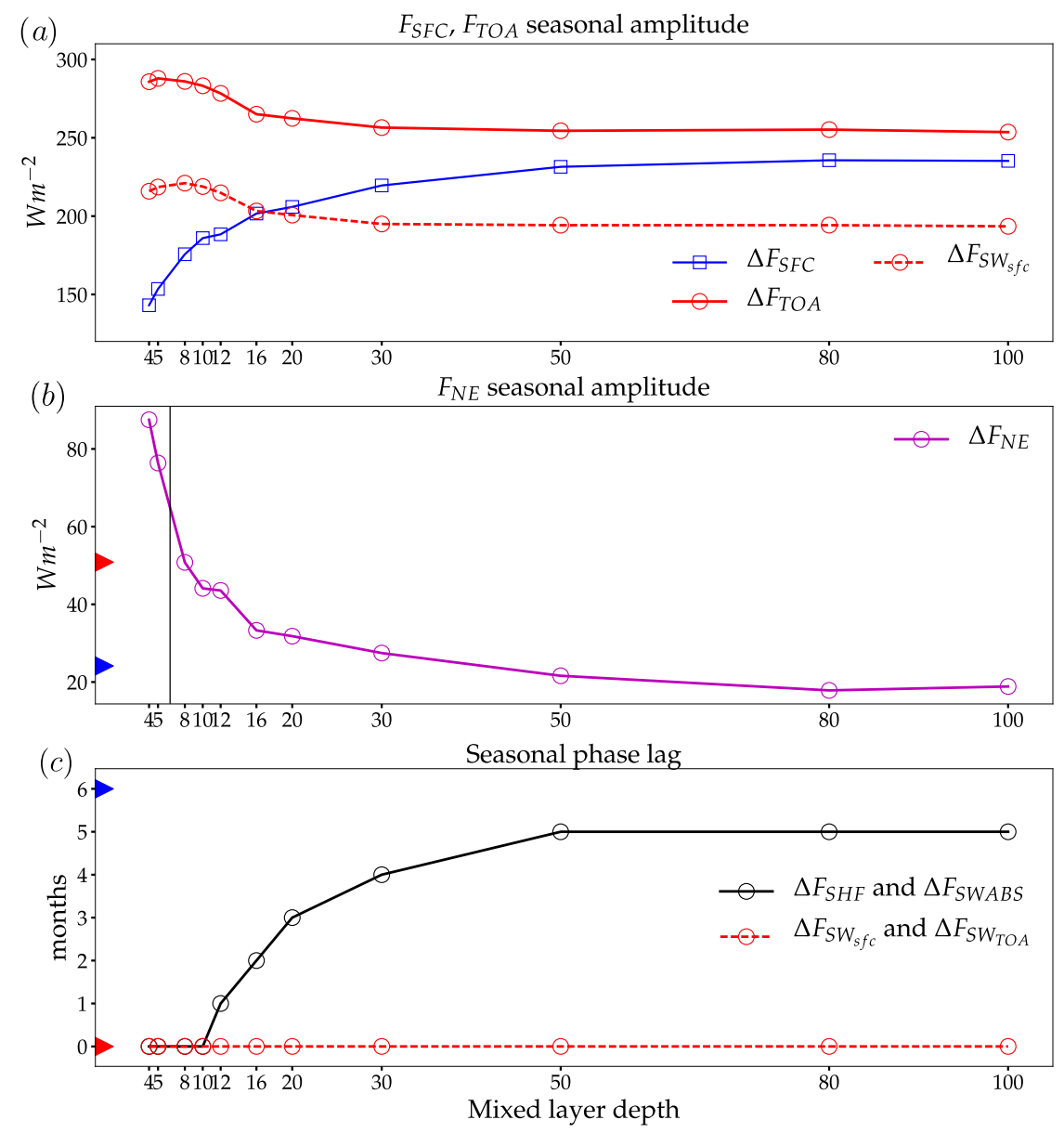

FIG. 2. Seasonal amplitude of (a) TOA radiation (red), surface flux (blue), and surface shortwave radiation (red dashed) and (b) net energy input (magenta) as a function of slabocean mixed layer depth. The black vertical line denotes $e$-folding depth for net energy input. (c) Phase difference between seasonal evolution of atmospheric shortwave absorption and surface heat flux (black) and surface shortwave radiation and TOA shortwave radiation (red dashed) as a function of slab-ocean mixed layer depth. Data from Isca simulations. The triangles on the $y$ axis denote values in the $\mathrm{NH}$ (red) and SH (blue) in the ERA-Interim.

planetary albedo of $\alpha=0.3$ is prescribed in Isca. The GFDL simulations use a multiband radiation parameterization (Freidenreich and Ramaswamy 1999), the relaxed Arakawa-Schubert convection scheme (Moorthi and Suarez 1992) and are configured with finite-volume grid with uniform horizontal resolution of $2.8^{\circ}$ (equivalent to $\mathrm{T} 42$ spectral), and 48 unevenly spaced sigma levels. Thus, the two GCMs differ in their convection schemes and the inclusion of cloud radiative effects.

Both aquaplanets are configured as follows: ocean energy flux convergence is zero, obliquity is $23.4^{\circ}$, eccentricity is zero and the concentration of greenhouse gases are: $\mathrm{CO}_{2}=348$ ppmv, $\mathrm{CH}_{4}=1650$ ppbv, $\mathrm{N}_{2} \mathrm{O}=306$ ppbv, and CFCs are zero. A climatological stratospheric ozone layer is also added to the model, which is hemispherically and zonally symmetric following Geen et al. (2018). We test the hypotheses outlined in section 2 by varying the mixed layer depth from 4 to $100 \mathrm{~m}$. All simulations are run for 40 years with the results representing the average over the last 30 years and both hemispheres (with SH data shifted by 6 months). The two GCMs yield consistent results, thus we present the Isca simulations in the section 4 and the GFDL simulations in appendix B.

\section{b. Energy balance model}

We use the Climlab EBM (Rose 2018), which solves an equation for surface temperature $T_{s}$ based on the TOA energy budget:

$$
C \frac{\partial T_{s}}{\partial t}=(1-\alpha) Q-\left(A+B T_{s}\right)+\frac{D_{\mathrm{ebm}}}{\cos \phi} \frac{\partial}{\partial \phi}\left(\cos \phi \frac{\partial T_{s}}{\partial \phi}\right)
$$



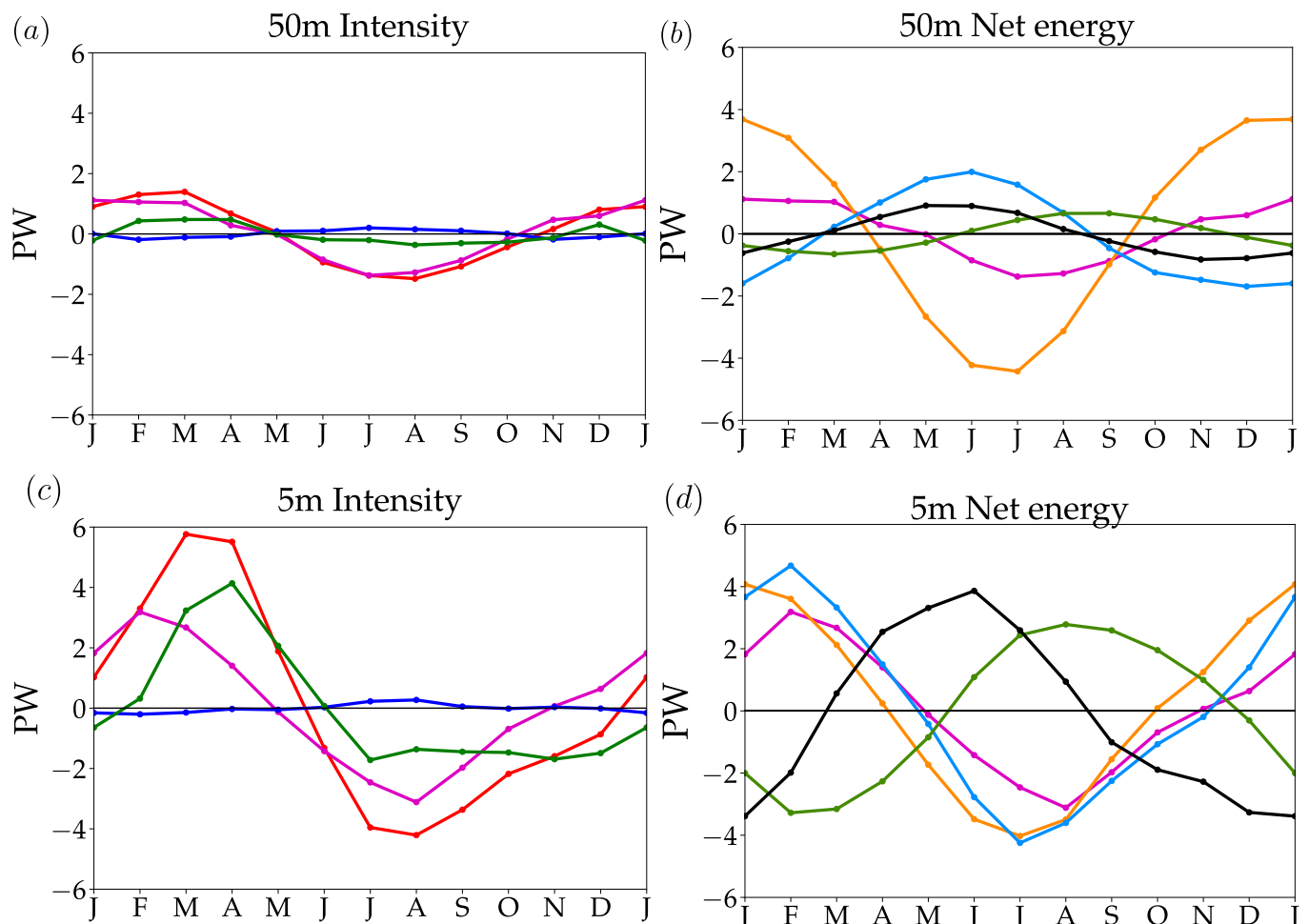

$(d)$

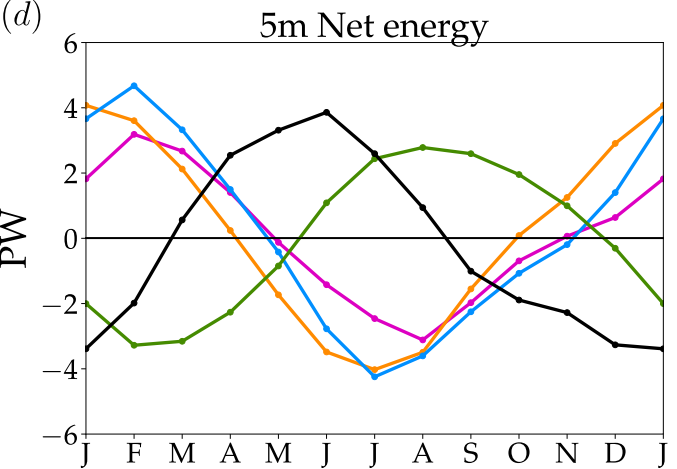

$$
\longrightarrow \Delta I \longrightarrow \Delta I_{N E} \longrightarrow-\Delta I_{S E} \longrightarrow-\Delta I_{M M}
$$

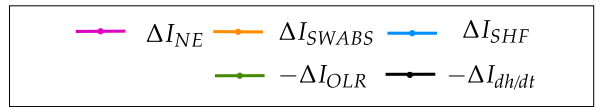

FIG. 3. (a),(c) Decomposition of storm track intensity as an anomaly relative to the annual-mean $\Delta I$ into contributions from net energy input $\Delta I_{\mathrm{NE}}$, stationary eddies $\Delta I_{\mathrm{SE}}$, and mean meridional circulation $\Delta I_{\mathrm{MM}}$. (b),(d) Decomposition of net energy input $\Delta I_{\mathrm{NE}}$ contribution to storm track intensity anomaly into atmospheric shortwave absorption $\Delta I_{\mathrm{SWABS}}$, surface heat flux $\Delta I_{\mathrm{SHF}}$, outgoing longwave radiation $\Delta I_{\mathrm{OLR}}$, and atmospheric storage $\Delta I_{d h / d t}$. Data from Isca simulations with (top) 50 and (bottom) $5 \mathrm{~m}$ slab-ocean mixed layer depth.

where $C=d \rho_{o} c_{p_{o}}$ is the effective (ocean plus atmosphere) heat capacity, $\alpha$ is the planetary albedo, $Q$ is the seasonally evolving solar insolation, $A+B T_{\mathrm{s}}$ is a parameterization of OLR, $D_{\text {ebm }}$ is the total diffusivity $\left(\mathrm{W} \mathrm{m}^{-2} \mathrm{~K}^{-1}\right)$. We used the following parameter values: $A=210 \mathrm{~W} \mathrm{~m}^{-2}, B=2 \mathrm{~W} \mathrm{~m}^{-2} \mathrm{~K}^{-1}$, and $\alpha=0.3$. Following Mbengue and Schneider (2018), the total diffusivity is

$$
D_{\text {ebm }}\left(\phi, \phi_{h}\right)=D_{x}+\left(D_{t}-D_{x}\right) S\left(\phi, \phi_{h}\right),
$$

where $\phi_{h}=25^{\circ}$ is the Hadley cell edge, $D_{x}=1.6 \mathrm{~W} \mathrm{~m}^{-2} \mathrm{~K}^{-1}$ is the extratropical diffusivity, $D_{t}=3.2 \mathrm{~W} \mathrm{~m}^{-2} \mathrm{~K}^{-1}$ is the tropical diffusivity, and $S\left(\phi, \phi_{h}\right)=(1 / 2)(1-\tanh$ $\left.\left\{\pi\left[\left(\phi-\phi_{h}\right) / \phi_{h}\right]\right\} \tanh \left\{\pi\left[\left(\phi+\phi_{h}\right) / \phi_{h}\right]\right\}\right)$.

The EBM is a dry model; thus, the storm track is defined differently than in the MSE framework. The storm track position $\phi_{s}$ is defined as the latitude where the extratropical eddy energy flux divergence is zero; that is, $\left.(\partial / \partial \phi)\left[\cos \phi\left(\partial T_{s} / \partial \phi\right)\right]\right|_{\phi_{s}}=0$. The storm track intensity $I_{\text {EBM }}$ is the value of extratropical energy flux at the storm track position; that is, $I_{\mathrm{EBM}}=-\left.2 \pi a^{2} \cos \phi_{s} D_{\mathrm{ebm}}\left(\partial T_{s} / \partial \phi\right)\right|_{\phi_{s}}$. In the EBM, TOA energy balance means that the intensity can be decomposed as follows:

$$
\Delta I_{\mathrm{EBM}}=\Delta I_{\mathrm{NE}}=\Delta I_{\mathrm{TOA}}-\Delta I_{C d T / d t},
$$

where $\Delta I_{\mathrm{TOA}}$ and $\Delta I_{C d T / d t}$ are the TOA radiation and the effective storage contributions, respectively. In the EBM the mixed layer depth controls the effective storage contribution, which cannot be separated into surface flux (ocean storage) and atmospheric storage contributions because the EBM is based on TOA energy balance.

\section{Results}

\section{a. Testing mixed layer depth hypothesis in the aquaplanet}

The slab-ocean aquaplanet simulations show that in the limit of large mixed layer depth TOA and surface 

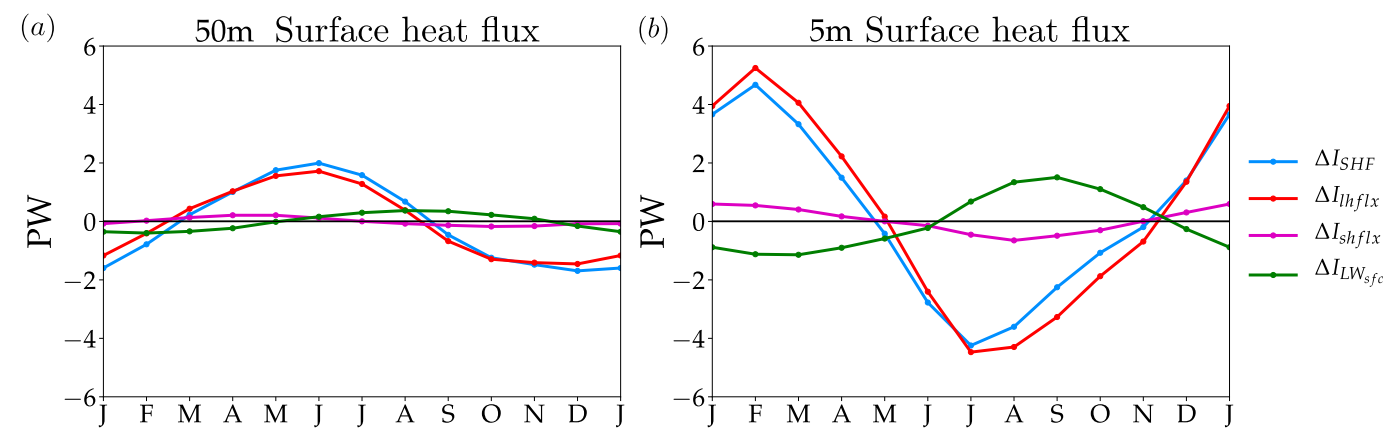

FIG. 4. Decomposition of surface heat flux contribution to storm track intensity as an anomaly relative to the annual-mean $\Delta I_{\mathrm{SHF}}$ into contributions by latent heat flux $\Delta I_{\mathrm{lhfl}}$, sensible heat flux $\Delta I_{\text {shflx }}$, and surface longwave radiation $\Delta I_{\mathrm{LW}_{\mathrm{sc}}}$. Data from Isca simulations with (a) 50 and (b) 5 m slab-ocean mixed layer depth.

fluxes are of similar magnitude, that is, $\Delta F_{\mathrm{TOA}} \approx \Delta F_{\mathrm{SFC}}$ (Fig. 2a), and net energy input is small (Fig. 2b). Shortwave absorption is 5 months out of phase with surface heat fluxes (Fig. 2c). This agrees well with the hypothesized 6-month phase lag between shortwave absorption and surface heat fluxes for large mixed layer depth. The 1-month discrepancy is attributed to the small but nonzero OLR contribution [see (6)]. Thus, the simulations confirm the large mixed layer depth hypothesis thus far. In addition, the slab-ocean aquaplanet simulations show that in the limit of small mixed layer depth TOA fluxes are larger than surface fluxes, that is, $\Delta F_{\mathrm{TOA}}>\Delta F_{\mathrm{SFC}}$ (Fig. 2a), and net energy input is large (Fig. 2b). The change in surface flux with mixed layer depth is not associated with surface shortwave radiation (cf. blue and dashed red lines, Fig. 2a). Furthermore, (a)

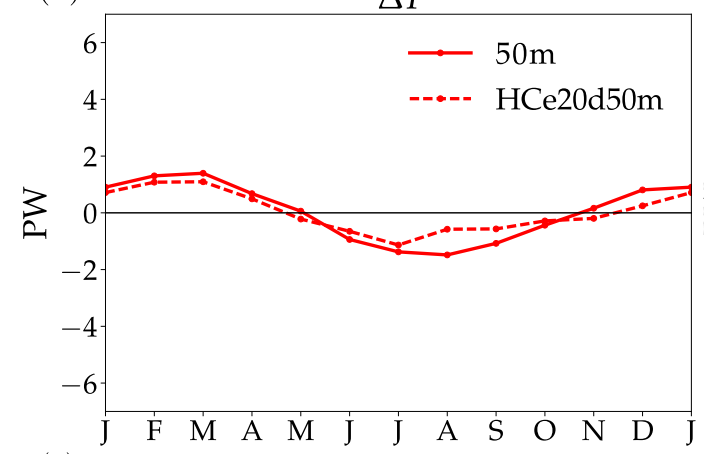

(c)

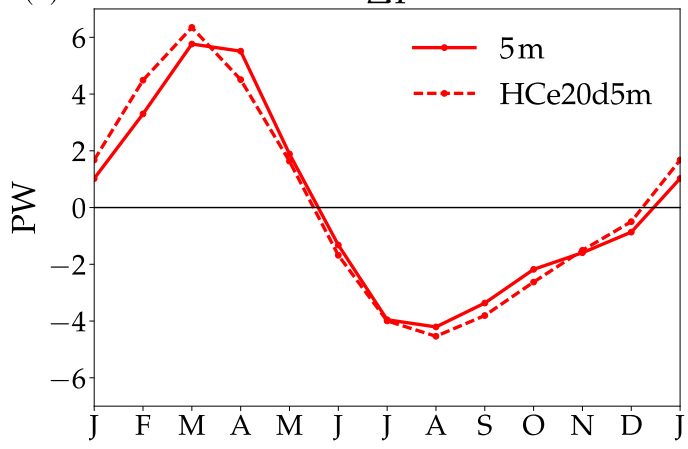

(b)

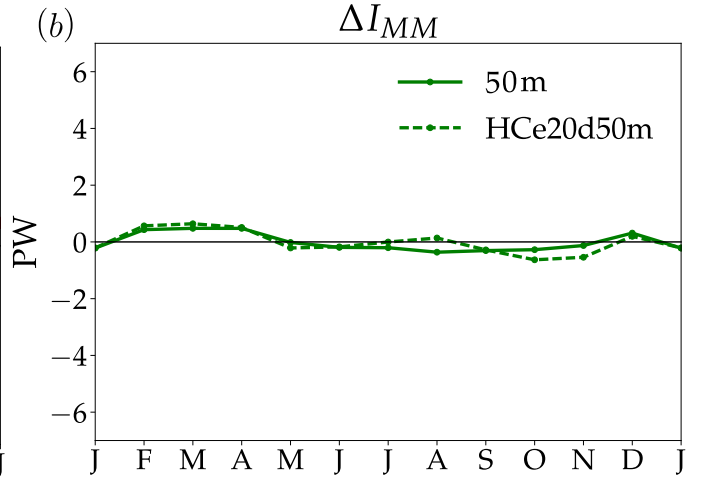

$(d)$

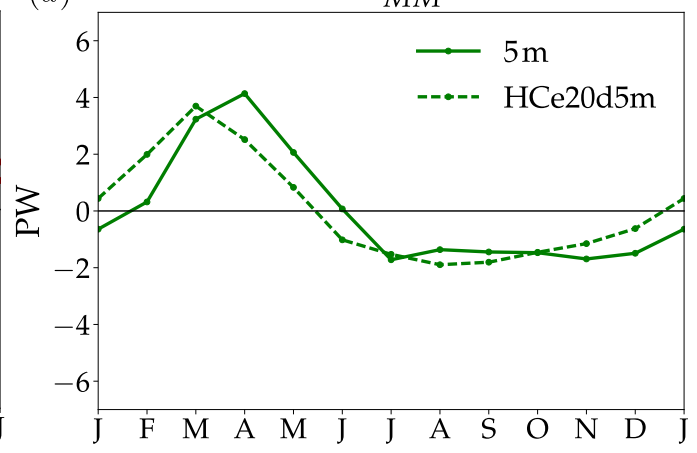

FIG. 5. (top) Seasonal evolution of (a) storm track intensity $\Delta I$ as an anomaly relative to the annual mean and (b) contribution from mean meridional circulation $\Delta I_{\mathrm{MM}}$ with $50 \mathrm{~m}$ slab-ocean mixed layer depth (solid) and HC experiment with $5 \mathrm{~m}$ mixed layer depth equatorward of $20^{\circ}$ and $50 \mathrm{~m}$ depth elsewhere (dashed). (bottom) Seasonal evolution of (c) storm track intensity $\Delta I$ as an anomaly relative to the annual mean and (d) contribution from mean meridional circulation with $5 \mathrm{~m}$ slab-ocean mixed layer depth (solid) and HC experiment with $50 \mathrm{~m}$ mixed layer depth equatorward of $20^{\circ}$ and $5 \mathrm{~m}$ elsewhere (dashed). Data from Isca simulations. 
shortwave absorption is in phase with surface heat fluxes (Fig. 2c) for small mixed layer depth. Thus, the simulations also confirm the small mixed layer depth hypothesis thus far. Finally, the critical depth, estimated as the $e$-folding depth of the net energy input as a function of mixed layer depth, is $6.5 \mathrm{~m}$ (black vertical line, Fig. 2b). This agrees well with the $10 \mathrm{~m}$ scaling estimate [see (8)].

In what follows, we choose 5 and $50 \mathrm{~m}$ as representative small and large slab-ocean mixed layer depths. The large mixed layer depth limit is reminiscent of the $\mathrm{SH}$ where the seasonality of net energy input is small and surface heat fluxes are out of phase with shortwave absorption (blue triangles, Figs. $2 \mathrm{~b}, \mathrm{c}$ ). In contrast, the small mixed layer depth limit is reminiscent of the $\mathrm{NH}$ where the seasonality of net energy input is large and surface heat fluxes are in phase with shortwave absorption (red triangles, Figs. 2b,c).

\section{1) EFFECT OF MIXED LAYER DEPTH ON STORM TRACK INTENSITY}

The slab-ocean aquaplanet simulations with large mixed layer depth exhibit small seasonality of storm track intensity (red line, Fig. 3a) following small seasonality of net energy input (magenta line, Fig. 3a). The seasonality of net energy input is small because shortwave absorption is out of phase with surface heat fluxes and OLR (cf. orange, blue and green lines, Fig. 3b). The surface heat flux seasonality is dominated by the latent heat flux contribution (Fig. 4a). In addition, the mean meridional circulation (green line, Fig. 3a), stationary eddy (blue line, Fig. 3a), and atmospheric storage (black line, Fig. 3b) contributions are small. Thus, the simulations confirm the intensity hypothesis for large mixed layer depth.

The slab-ocean aquaplanet simulations with small mixed layer depth exhibit large storm track seasonality (red line, Fig. 3c) following the large seasonality of net energy input (magenta line, Fig. 3c). Net energy input is large because shortwave absorption is in phase with surface heat fluxes (cf. orange and blue lines, Fig. 3d). The surface heat flux seasonality is very large and dominated by the latent heat flux contribution (Fig. 4b). However, contrary to the assumptions underlying our hypothesis the mean meridional circulation (green line, Fig. 3c) and atmospheric storage (black line, Fig. 3d) contributions are large. Thus, the simulations do not exactly confirm the intensity hypothesis for small mixed layer depth.

The slab-ocean aquaplanet simulations show that in the limit of small mixed layer depth, surface heat fluxes are not solely responsible for the large seasonality of storm track intensity; the mean meridional circulation and atmospheric storage contributions are both important. The large atmospheric storage contribution with
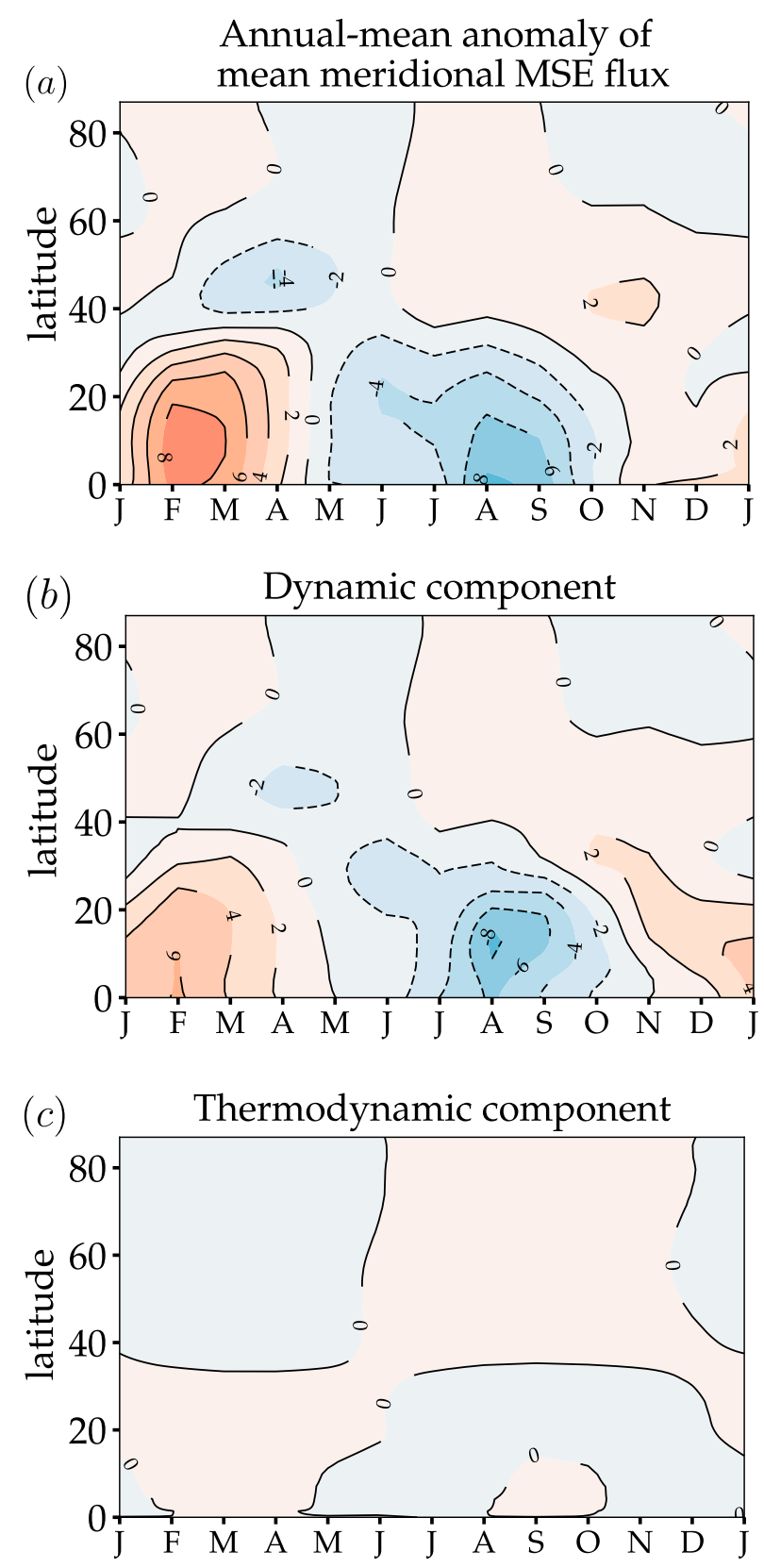

FIG. 6. Seasonal evolution of (a) the contribution by mean meridional MSE flux $\langle[\bar{v}][\bar{m}]\rangle$ to storm track intensity as an anomaly relative to the annual mean decomposed into (b) dynamic $\left\langle(\Delta[\bar{v}])[m]_{a}\right\rangle$ and (c) thermodynamic $\left\langle[v]_{a} \Delta([\bar{m}])\right\rangle$ contributions for Isca simulation with $5 \mathrm{~m}$ slab-ocean mixed layer depth.

small mixed layer depth is consistent with the seasonal amplitude of atmospheric temperature increasing with decreasing mixed layer depth (Donohoe et al. 2014). To better understand the mean meridional circulation contribution to storm track intensity for small mixed layer depth, we consider two additional questions: 1 ) Is the mean meridional circulation contribution driven 

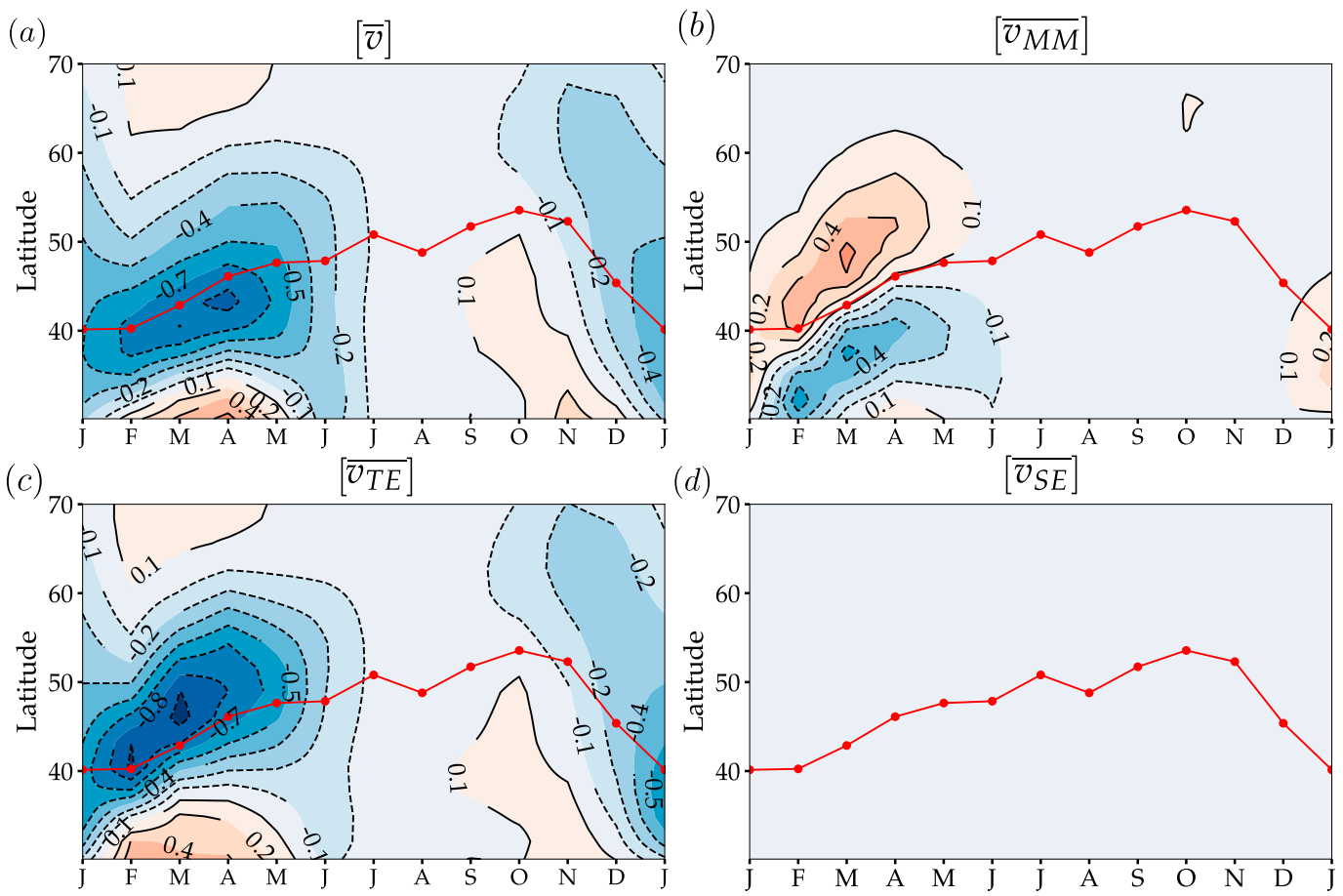

FIG. 7. Decomposition of the (a) mean meridional flow at $250 \mathrm{hPa}$ into contributions from the (b) mean meridional circulation $\overline{\left[v_{\mathrm{MM}}\right]}$ and (c) transient eddy $\overline{\left[v_{\mathrm{TE}}\right]}$ and (d) stationary eddy $\left[\overline{v_{\mathrm{SE}}}\right]$ momentum flux divergence using the zonal-mean zonal momentum budget for Isca simulation with $5 \mathrm{~m}$ slab-ocean mixed layer depth.

locally by Ferrel cell dynamics or nonlocally via interactions with the Hadley cell, and 2) is the seasonality of the mean meridional circulation MSE flux associated with thermodynamic or dynamic changes?

To quantify the role of nonlocal Hadley cell seasonality for the mean meridional MSE flux in the extratropics, we configure two additional slab-ocean aquaplanet simulations: 1) $5 \mathrm{~m}$ mixed layer depth in the tropics $\left(20^{\circ} \mathrm{S}-20^{\circ} \mathrm{N}\right)$ with $50 \mathrm{~m}$ mixed layer depth elsewhere and 2) $50 \mathrm{~m}$ mixed layer depth in the tropics with $5 \mathrm{~m}$ mixed layer depth elsewhere. The results show that the seasonal storm track intensity and mean meridional circulation contribution are mostly independent of tropical mixed layer depth (Fig. 5). Thus, local Ferrel cell dynamics control the mean meridional circulation contribution to storm track intensity for small mixed layer depth.

To understand the importance of thermodynamic versus dynamic changes for the seasonality of mean meridional circulation MSE flux, we decompose the flux into dynamic and thermodynamic contributions (cf. Seager et al. 2010); that is,

$$
\Delta\langle[\bar{v}][\bar{m}]\rangle \approx \underbrace{\left\langle(\Delta[\bar{v}])[m]_{a}\right\rangle}_{\text {Dynamic }}+\underbrace{\left\langle[v]_{a} \Delta([\bar{m}])\right\rangle}_{\text {Thermodynamic }},
$$

where $[m]_{a}$ and $[v]_{a}$ are annual, zonal-mean MSE and meridional wind, respectively. Overall, the dynamic contribution dominates over the thermodynamic contribution for small mixed layer depth (Fig. 6). Thus, the seasonal dynamical changes in the Ferrel cell are important for storm track intensity in the limit of small mixed layer depth.

To better understand what controls the dynamical changes in the Ferrel cell, we use the zonal-mean zonal momentum budget to decompose the mean meridional flow into mean meridional circulation, stationary eddy and transient eddy contributions (cf. Seager et al. 2003; Schneider and Bordoni 2008):

$$
\begin{aligned}
& {[\bar{v}]=\underbrace{\frac{1}{f}\left[\frac{\partial[\bar{u}]}{\partial t}-[\bar{\zeta}][\bar{v}]+[\bar{\omega}] \frac{\partial[\bar{u}]}{\partial p}\right]}_{\left[\overline{v_{\mathrm{MM}}}\right]}} \\
& \underbrace{+\frac{1}{f}\left[\frac{\partial\left[\bar{u}^{*} \bar{\omega}^{*}\right]}{\partial p}+\frac{1}{a \cos ^{2} \phi} \frac{\partial}{\partial \phi}\left(\cos ^{2} \phi\left[\bar{u}^{*} \bar{v}^{*}\right]\right)\right]}_{\left[\overline{v_{\mathrm{SE}}}\right]} \\
& +\underbrace{\frac{1}{f}\left[\frac{\partial\left[\overline{u^{\prime} \omega^{\prime}}\right]}{\partial p}+\frac{1}{a \cos ^{2} \phi} \frac{\partial}{\partial \phi}\left(\cos ^{2} \phi\left[\overline{u^{\prime} v^{\prime}}\right]\right)\right]}_{[\overline{\mathrm{TE}}]},
\end{aligned}
$$




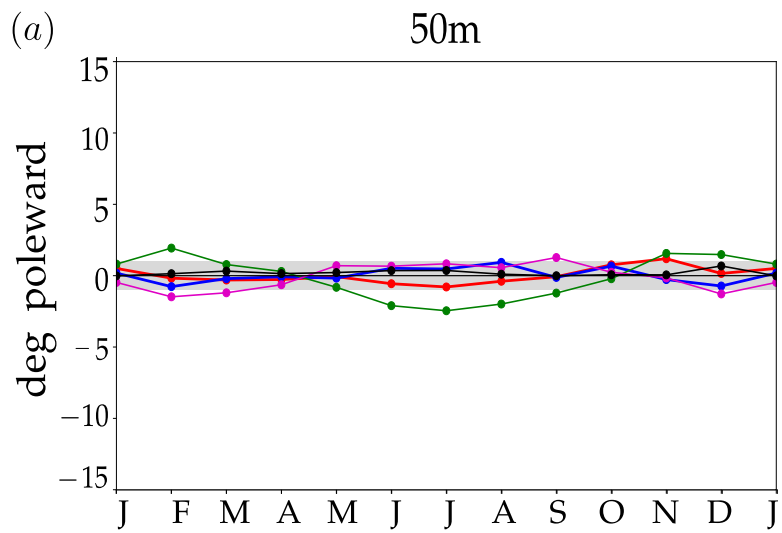

(b)
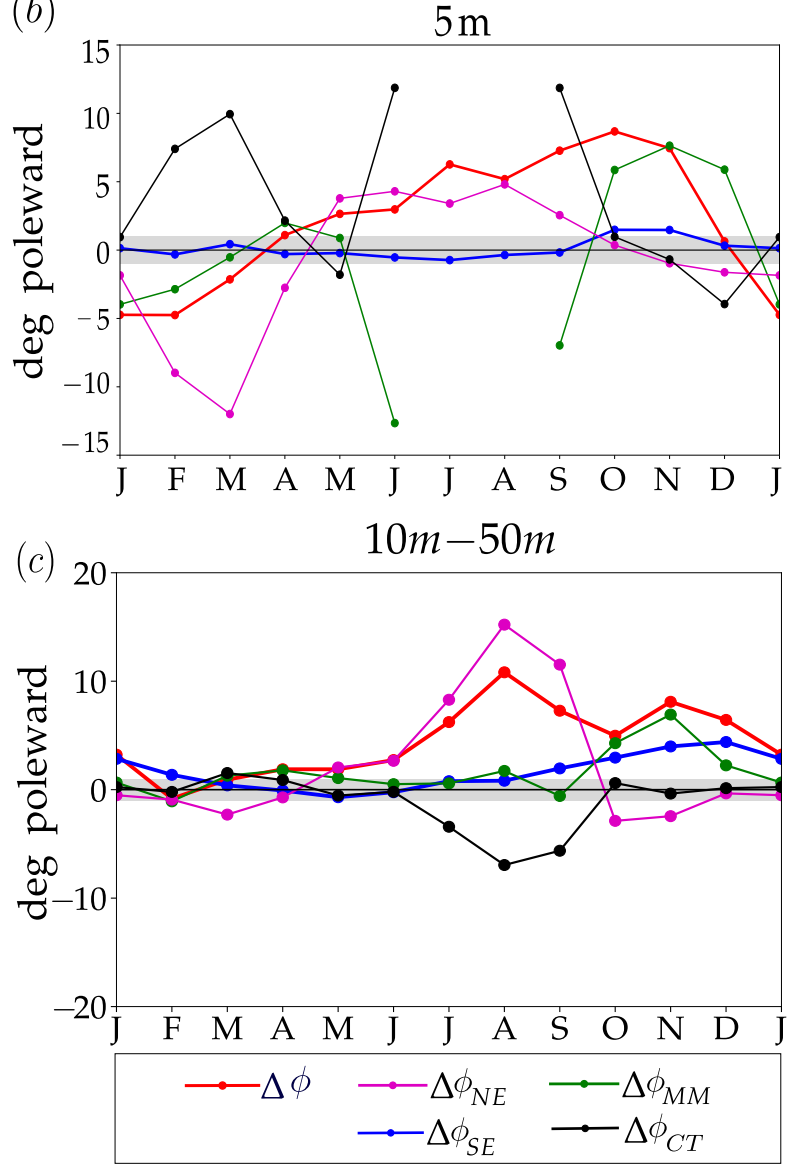

FIG. 8. Seasonal evolution of storm track position as an anomaly relative to the annual-mean $\Delta \phi$ decomposed into contributions from net energy input $\Delta \phi_{\mathrm{NE}}$, mean meridional circulation $\Delta \phi_{\mathrm{MM}}$, and stationary eddies $\Delta \phi_{\mathrm{SE}}$ for Isca simulations with (a) $50 \mathrm{~m}$, (b) $5 \mathrm{~m}$, and (c) $10 \mathrm{~m}$ minus $50 \mathrm{~m}$ slab-ocean mixed layer depth.

where $f$ is the Coriolis parameter, $\zeta$ is relative vorticity, and $\omega$ is vertical velocity. Overall, the transient eddy component $\left[\overline{v_{\mathrm{TE}}}\right]$ dominates the seasonality of the mean meridional flow (Ferrel cell) in the upper troposphere $(250 \mathrm{hPa})$ for small mixed layer depth (Fig. 7) consistent with previous work (Bordoni and Schneider 2008). The mean meridional flow in the upper troposphere reaches its extremum during April (Fig. 7a) consistent with the mean meridional circulation contribution to storm track intensity (green line, Fig. 3c). According to the momentum budget decomposition, the mean meridional flow extremum in April is due to both the transient eddy $\left[\overline{v_{\mathrm{TE}}}\right]$ and mean meridional circulation $\left[\overline{v_{\mathrm{MM}}}\right]$ contributions.

\section{2) EFFECT OF MIXED LAYER DEPTH ON STORM TRACK POSITION}

The slab-ocean aquaplanet simulations with large mixed layer depth exhibit small seasonal storm track shift (red line, Fig. 8a) following the small seasonality of net energy input (magenta, Fig. 8a). The mean meridional circulation (green line, Fig. 8a), stationary eddy (blue line, Fig. 8a) and atmospheric storage (black line, Fig. 8a) contributions are small. Thus, the simulations confirm the storm track position hypothesis for the large mixed layer depth limit.

The slab-ocean aquaplanet simulations with small mixed layer depth exhibit a large seasonal storm track shift (red line, Fig. 8b). The seasonal shift is so large that the MSE framework breaks down (the cross term is very large). Therefore, we cannot confirm that the large shift is due to large net energy input as hypothesized. However, it is clear that the mean meridional circulation (green line, Fig. 8b) and cross term (black line, Fig. 8b) contributions are not small.

To avoid large shifts and a breakdown of the MSE framework, we quantify the seasonal storm track shift between large $(50 \mathrm{~m})$ and intermediate $(10 \mathrm{~m})$ mixed layer depths. Since the annual-mean storm track position for the intermediate mixed layer depth is poleward of the position for the large depth, the shift difference is always positive. The intermediate minus large mixed layer depth shows that the net energy input contribution dominates during summer (JuneAugust) and the mean meridional circulation contribution dominates during November (Fig. 8c). Thus, consistent with the intensity results, in the limit of small mixed layer depth surface fluxes are not solely responsible for seasonal shifts of the storm track, the mean meridional circulation contribution is also important and is dominated by seasonal dynamical changes in the Ferrel cell.

\section{3) CONNECTION TO THE OBSERVED STORM TRACKS}

The storm track seasonality for the slab-ocean aquaplanet simulation with large mixed layer depth 


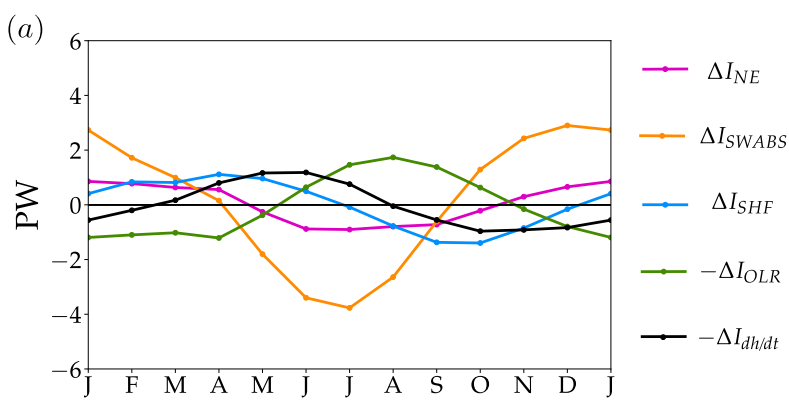

FIG. 9. As in Fig. 3b, but for $50 \mathrm{~m}$ slab-ocean mixed layer depth equatorward of $55^{\circ}$ and $2 \mathrm{~m}$ depth poleward of $55^{\circ}$.

exhibits several similarities with the SH storm track on Earth. First, the large mixed layer depth simulation reproduces the small seasonality of storm track intensity and position (cf. red lines, Figs. 1a, 3a, and $8 \mathrm{a}$ ) associated with the small seasonality of net energy input (cf. magenta lines, Figs. 1a and 3a). Second, the large mixed layer depth simulation also reproduces the out-of-phase relationship between the shortwave absorption and surface heat flux contributions to seasonal intensity seen in the $\mathrm{SH}$ (cf. orange and blue lines, Figs. 1c and 3b). However, the amplitudes of the OLR and surface heat flux contributions to intensity for the large mixed layer depth simulation are different than those in the SH (cf. green and blue lines, Figs. 1c and 3b). More specifically, the surface heat flux contribution is larger than the OLR contribution in the $\mathrm{SH}$, whereas the opposite is true for the large mixed layer depth simulation.
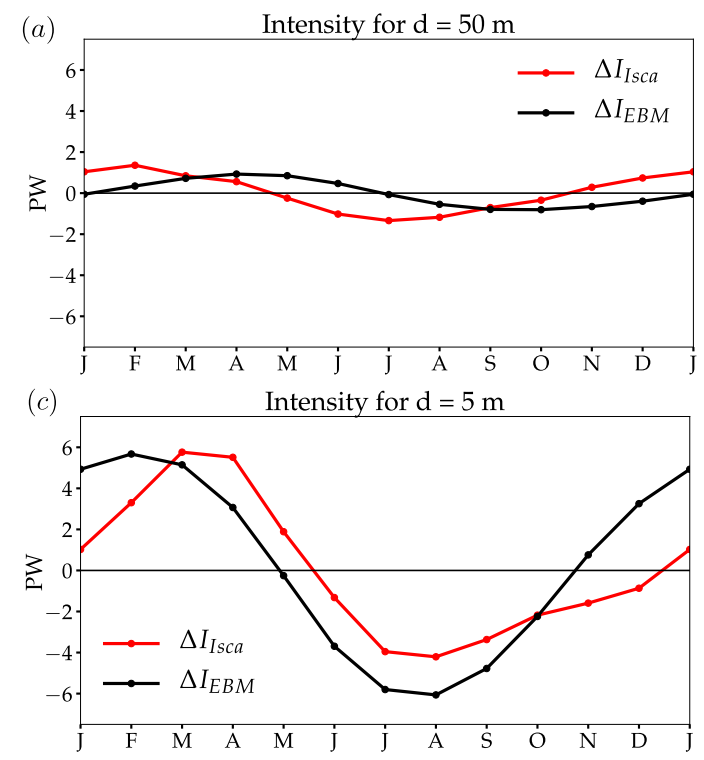

An important difference between the $\mathrm{SH}$ and an aquaplanet simulation with large mixed layer depth is Antarctica. To test whether Antarctica is important for storm track seasonality in the $\mathrm{SH}$, we configured a simulation with a large mixed layer depth $(50 \mathrm{~m})$ and a polar region that mimics Antarctica. The Antarctic region is mimicked by a region with high albedo $(\alpha=0.7)$ small mixed layer depth $(2 \mathrm{~m})$ and zero latent heat flux poleward of $55^{\circ}$ (latent heat flux is multiplied by $\beta=0$ poleward of $55^{\circ}$ ). The seasonal storm track intensity with a polar region that mimics Antarctica exhibits an OLR contribution that is larger than the surface heat flux contribution consistent with the SH (Fig. 9). Thus, the storm track seasonality in a zonally symmetric slabocean aquaplanet with a large mixed layer depth $(50 \mathrm{~m})$ and a polar region that mimics Antarctica is a good idealization of the SH storm track.

The storm track seasonality for the small mixed layer depth slab-ocean aquaplanet simulation is large similar to the NH storm track (cf. red lines, Figs. 1b, 3c, and 8b) and associated with the large seasonality of net energy input (cf. magenta lines, Figs. $1 \mathrm{~b}$ and $3 \mathrm{c}$ ). However, there are also important differences. First, net energy input seasonality dominates the intensity in the $\mathrm{NH}$ whereas in the aquaplanet simulations with small mixed layer depth, net energy input and mean meridional circulation play an equal role (cf. magenta and green lines, Figs. $1 \mathrm{~b}$ and $3 \mathrm{c}$ ). Second, while the phase relationship between shortwave absorption and surface heat fluxes is similar, the aquaplanet surface heat fluxes, OLR and atmospheric storage contributions are much larger than
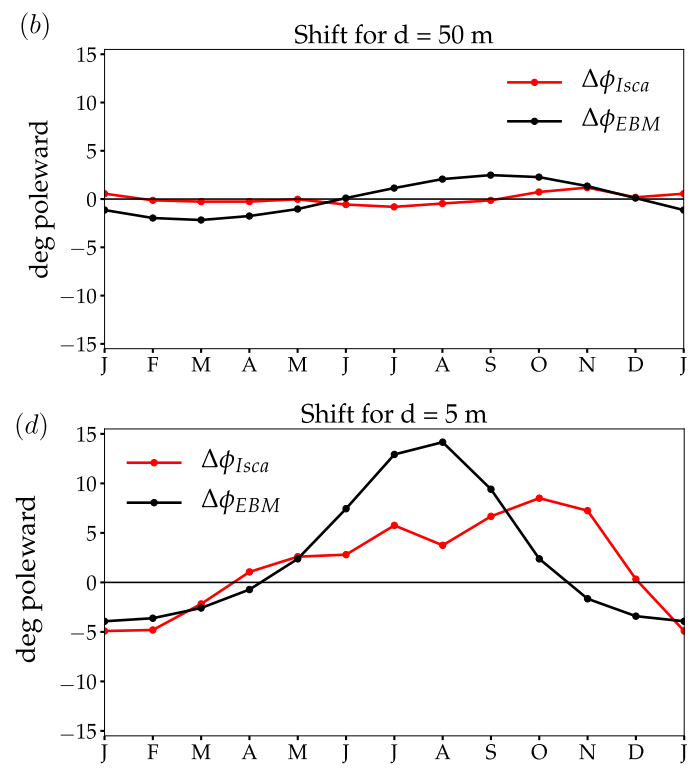

FIG. 10. Storm track (a),(c) intensity and (b),(d) shift as an anomaly relative to the annual mean for the (top) 50 and (bottom) $5 \mathrm{~m}$ mixed layer depth for Isca (red) and EBM (black) simulations. 

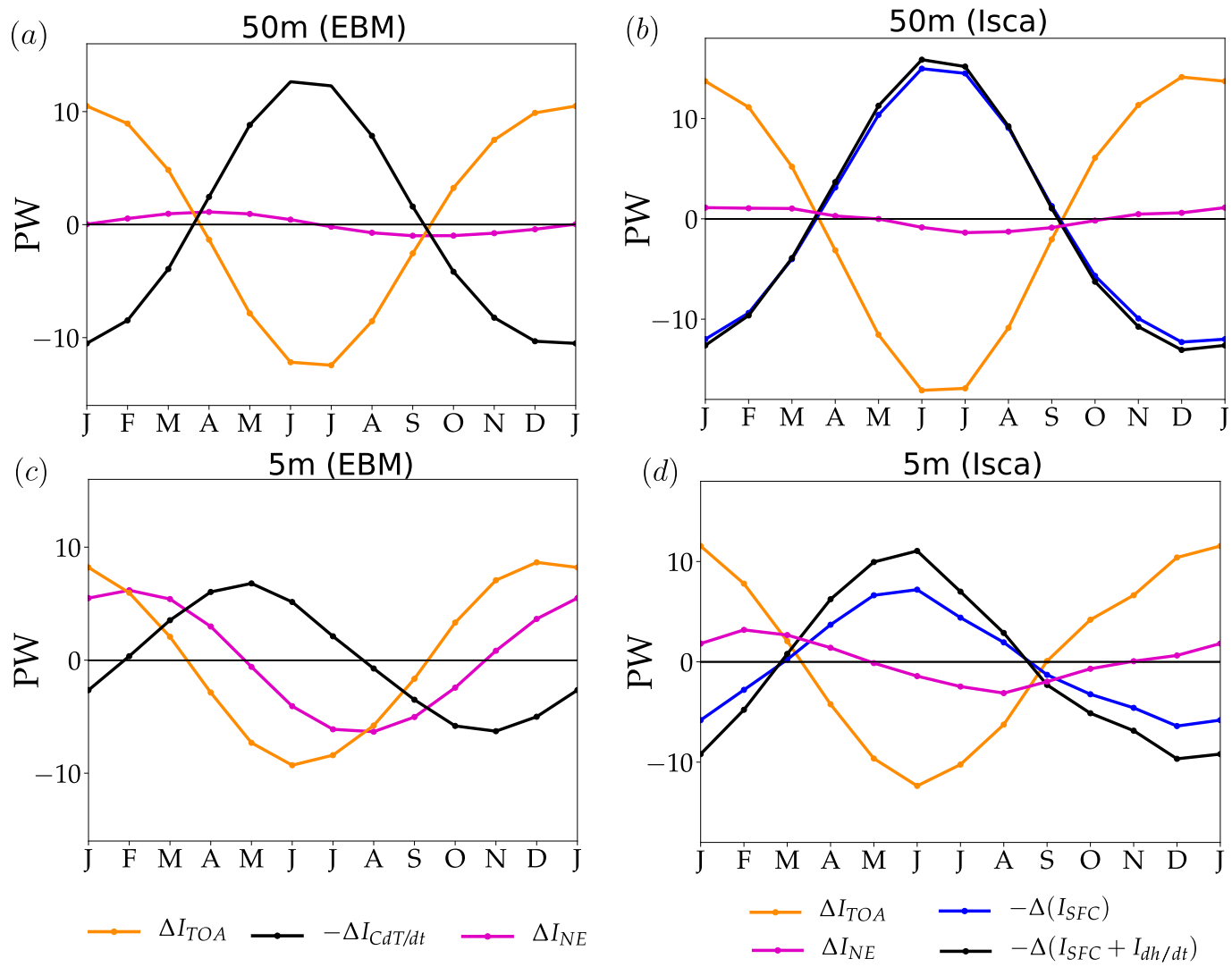

FIG. 11. Decomposition of storm track intensity as an anomaly relative to the annual-mean $\Delta I$ into contributions from net energy input $\Delta I_{\mathrm{NE}}$, TOA radiation $\Delta I_{\mathrm{TOA}}$, effective storage $-\Delta I_{C d T / d t}$, and surface fluxes $\Delta I_{\mathrm{SFC}}$. Data are from (a),(c) EBM and (b),(d) Isca simulations for (top) 50 and (bottom) $5 \mathrm{~m}$ slab-ocean mixed layer depth.

those in the NH (cf. blue, green, and black lines, Figs. 1d and 3d). Third, while the seasonality of storm track intensity in the $\mathrm{NH}$ and the small mixed layer depth aquaplanet simulations both involve a contribution from the stationary circulation (mean meridional circulation for the slab-ocean aquaplanet and stationary eddies for the $\mathrm{NH}$ ), the effects are opposite. In the $\mathrm{NH}$ the stationary eddy contribution opposes the seasonality of storm track intensity (blue and red lines, Fig. 1b), consistent with stationary eddies generating downgradient MSE fluxes, and accounts for a midwinter minimum. Whereas for the small mixed layer depth, the mean meridional circulation is approximately in phase with storm track intensity (green and red lines, Fig. 3c), consistent with the Ferrel cell generating upgradient MSE fluxes, and there is no midwinter minimum (Figs. $3 \mathrm{c}$ and $\mathrm{C} 1$ and $\mathrm{C} 2$ in appendix $\mathrm{C}$ ). Thus, the $\mathrm{NH}$ and aquaplanet simulation with small mixed layer depth are in different regimes. Similar differences occur for storm track position.

\section{b. Connecting the aquaplanet and EBM results}

As discussed in the introduction, several storm track frameworks are based on mean temperature.
Unfortunately, those frameworks do not predict temperature and do not include external parameters such as mixed layer depth. Thus, it is difficult to interpret the aquaplanet simulations using mean frameworks. To get around this issue we use an EBM because it depends on mixed layer depth and it predicts mean surface temperature (see section $3 \mathrm{~b}$ ). Here we quantify how varying the mixed layer depth in the EBM affects 1) storm track seasonality and 2) the mean surface temperature as compared to the aquaplanet. A comparison between the EBM, which has fixed annual-mean diffusivity, and the aquaplanet reveals the role of dynamical feedbacks for storm track seasonality. Since the mixed layer depth controls the effective storage [sum of surface fluxes (ocean storage) and atmospheric storage in the aquaplanet] in the EBM we use the EBM intensity decomposition [see (11)] when comparing it to the aquaplanet.

\section{1) EFFECT OF MIXED LAYER DEPTH ON STORM} TRACK AND COMPARISON WITH AQUAPLANET

The EBM with large mixed layer depth exhibits small seasonality of storm track intensity and position 

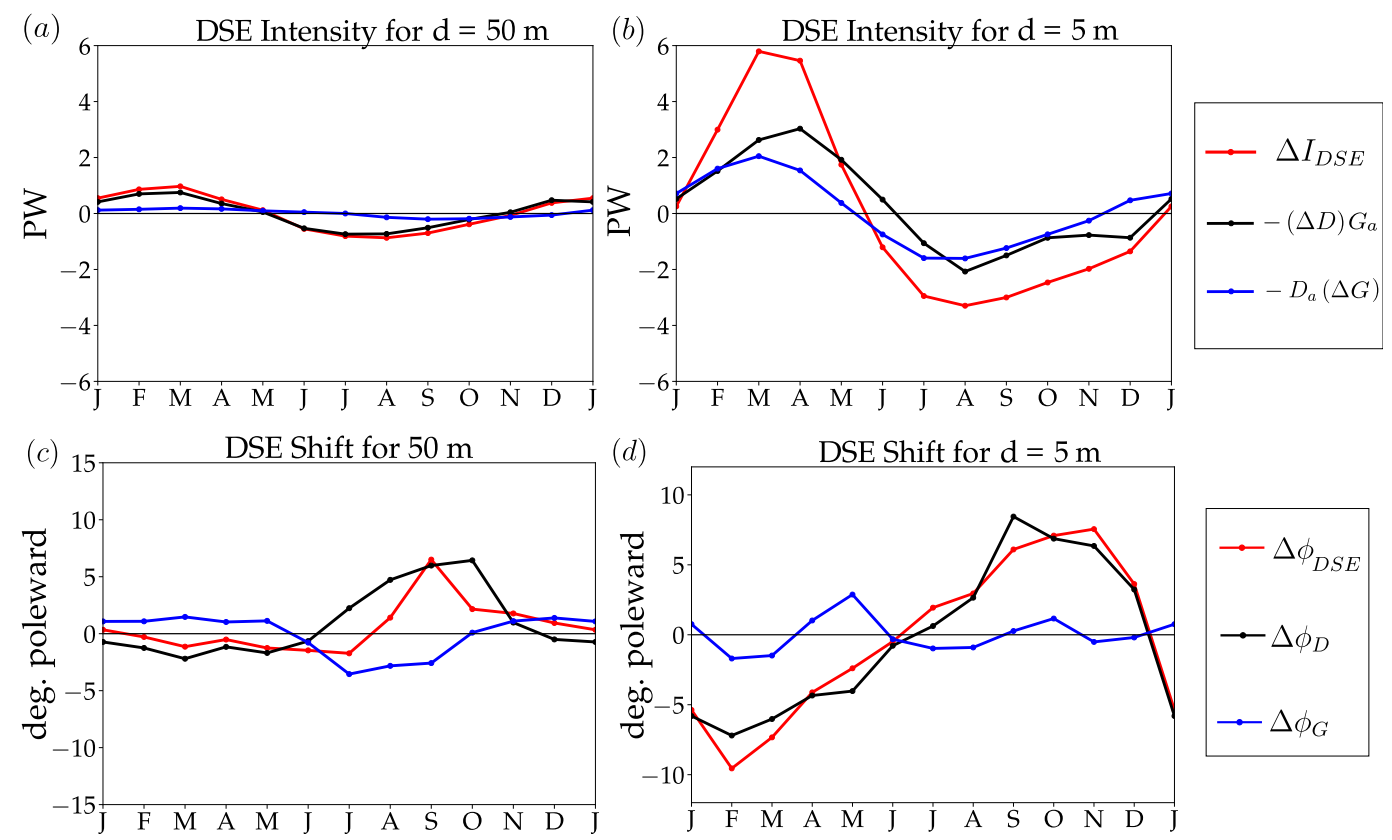

FIG. 12. Decomposition of storm track (a),(b) intensity and (c),(d) position defined using transient eddy DSE flux $\Delta I_{\mathrm{DSE}}$ as an anomaly relative to the annual mean into contribution from changes in diffusivity $\left[-(\Delta D) G_{a}, \Delta \phi_{D}\right]$, and changes in gradient $\left[-D_{a}(\Delta G), \Delta \phi_{G}\right]$. Data from Isca simulations with (left) 50 and (right) $5 \mathrm{~m}$ slab-ocean mixed layer depth.

consistent with the aquaplanet (cf. black and red lines, Figs. 10a,b). The small seasonality of storm track intensity in the EBM with large mixed layer depth is associated with small net energy input seasonality consistent with the aquaplanet (cf. magenta lines, Figs. 11a,b). The net energy input seasonality is small because effective storage damps TOA radiation (cf. orange and black lines, Figs. 11a,b). In the aquaplanet (a)
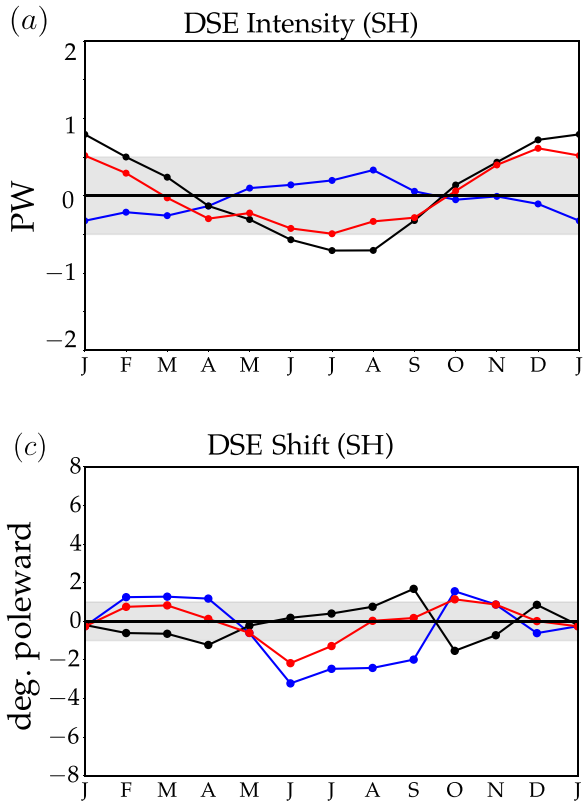

(b)

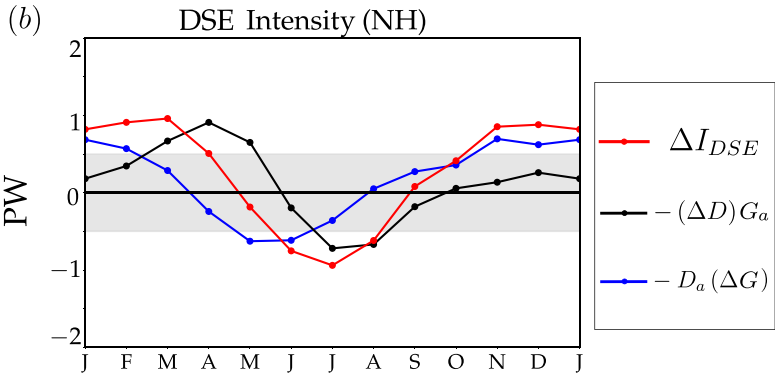

(d)

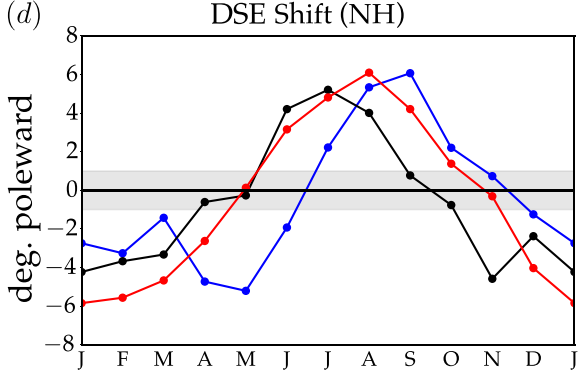

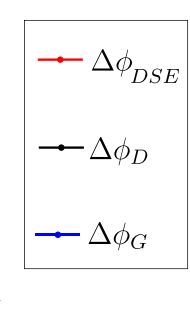

FIG. 13. Decomposition of storm track (a),(b) intensity and (c),(d) position defined using transient eddy DSE flux as an anomaly relative to the annual mean into contribution from changes in diffusivity $\left[-(\Delta D) G_{a}, \Delta \phi_{D}\right]$ and changes in gradient $\left[-D_{a}(\Delta G), \Delta \phi_{G}\right]$. (left) $\mathrm{SH}$ and (right) $\mathrm{NH}$ for ERA-Interim. 
(a)

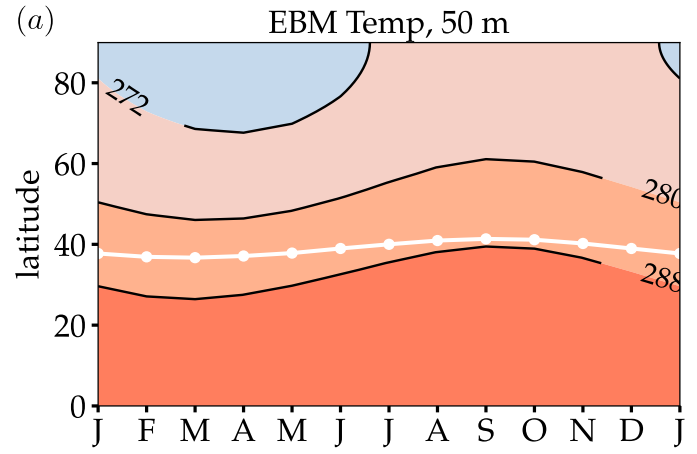

(c)

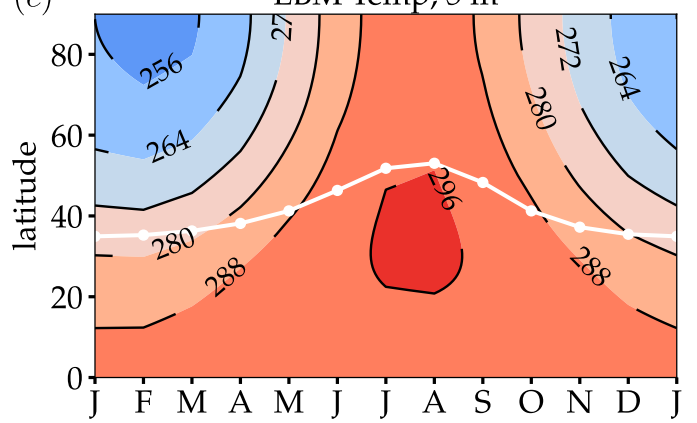

(b)

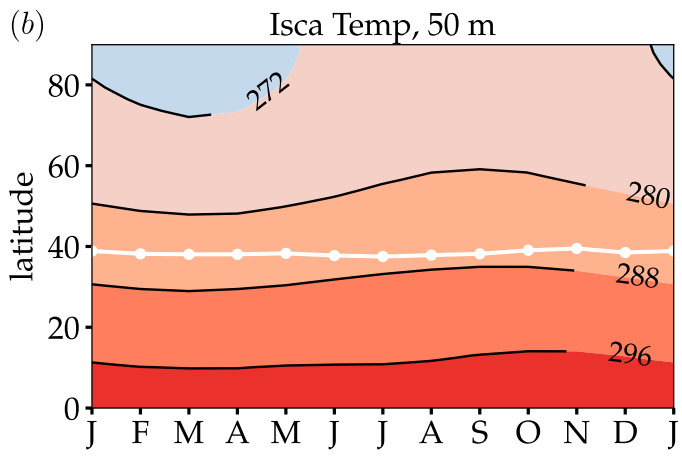

(d)

Isca Temp, $5 \mathrm{~m}$

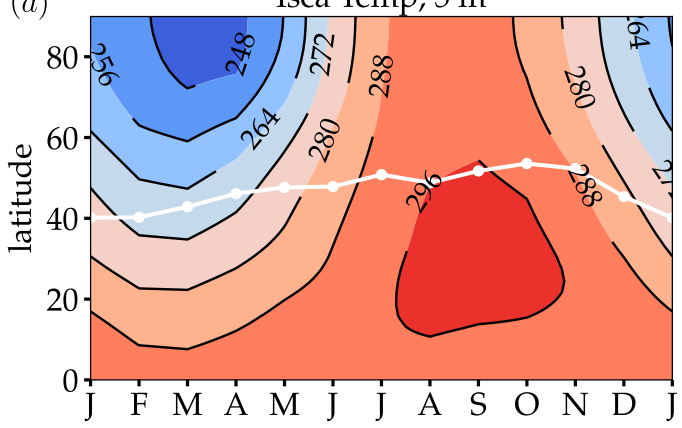

FIG. 14. Seasonal evolution of mean surface temperature for (a),(c) EBM and (b),(d) Isca simulations with (top) 50 and (bottom) $5 \mathrm{~m}$ mixed layer depth. White lines show the storm track position.

the effective storage is dominated by surface fluxes (cf. black and blue lines, Fig. 11b); that is, atmospheric storage is small. Thus, the compensation of TOA radiation by effective storage reflects the compensation of TOA radiation by surface fluxes (Fig. 2a), which is consistent with the large mixed layer depth hypothesis.

The EBM with small mixed layer depth exhibits large seasonality of storm track intensity and position consistent with the aquaplanet (cf. black and red lines, Figs. 10c,d). The large storm track seasonal intensity in the EBM is associated with large net energy input seasonality (Figs. 11c,d). The net energy input seasonality is large for small mixed layer depth because the effective storage contribution is phaseshifted by 1 month relative to the large mixed layer depth (cf. orange and black lines, Figs. 11a,c). In the aquaplanet the changes in seasonality of effective storage from large to small mixed layer depth reflect 1) a larger atmospheric storage contribution (difference between black and blue lines, Figs. 11b,d) and 2) a 1-month phase-shift of the surface flux contribution (cf. blue lines, Figs. 11b,d). The surface flux changes in the aquaplanet are due to surface heat flux changes rather than changes in surface shortwave radiation (red dashed line, Figs. 2a,c), which is consistent with the small mixed layer depth hypothesis.

While the EBM qualitatively captures the mixed layer depth dependence of storm track seasonality in the aquaplanet, it does not capture the quantitative behavior. In particular, the seasonality of storm track intensity and position in the aquaplanet are delayed relative to the EBM for small mixed layer depth (cf. black and red lines, Fig. 10). To better understand the different storm track seasonality in the aquaplanet and EBM we diagnose the aquaplanet diffusivity:

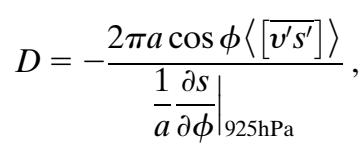

where $s$ is dry static energy (DSE). We focus on DSE because the EBM is a dry model. We separate storm track intensity anomalies relative to the annual mean into gradient and diffusivity contributions:

$$
\Delta I_{\mathrm{DSE}} \approx-D_{a}(\Delta G)-(\Delta D) G_{a},
$$

where the subscript " $a$ " refers to the annual-mean value and $G$ is the meridional DSE gradient at $925 \mathrm{hPa}$. 
According to the EBM the gradient term should dominate [first term on the right-hand side of (15)]. The decomposition shows that diffusivity changes dominate storm track seasonality in the aquaplanet with large mixed layer depth (red line, Fig. 12a) similar to the $\mathrm{SH}$ (red line, Fig. 13a). Gradient and diffusivity changes are important in the aquaplanet with small mixed layer depth (red and blue lines, Fig. 12b) similar to the $\mathrm{NH}$ (red line, Fig. 13b). They lead to a delay of storm track intensity relative to TOA radiation. Recall that the delayed storm track intensity in the aquaplanet with small mixed layer depth was associated with the mean meridional circulation contribution (green line, Fig. 3c). This suggests that the EBM does not capture the delayed seasonality of storm track intensity in the aquaplanet because it does not include dynamical feedbacks.

The seasonal storm track shift in the aquaplanet can also be decomposed into gradient and diffusivity contributions. In particular, the seasonal evolution of the transient eddy DSE flux divergence relative to the annual mean is

$$
\Delta F_{\mathrm{TE}, \mathrm{DSE}} \approx-\underbrace{\partial_{y}\left(D_{a} \Delta G\right)}_{\Delta F_{G}}-\underbrace{\partial_{y}\left(G_{a} \Delta D\right)}_{\Delta F_{D}},
$$

such that the storm track shift $\Delta \phi$ can be decomposed as

$$
\Delta \phi \approx \Delta \phi_{G}+\Delta \phi_{D}
$$

where

$\Delta \phi_{G}=\phi_{G}-\phi_{a}, \quad$ where $\left.\left(F_{\mathrm{TE}, \mathrm{DSE}, a}+\Delta F_{G}\right)\right|_{\phi_{G}}=0$,

$\Delta \phi_{D}=\phi_{D}-\phi_{a}, \quad$ where $\left.\left(F_{\mathrm{TE}, \mathrm{DSE}, a}+\Delta F_{D}\right)\right|_{\phi_{D}}=0$,

and $\phi_{a}$ is the annual-mean storm track position. Diffusivity changes dominate the seasonal storm track shift for large and small mixed layer depths (Figs. 12c,d). They also dominate seasonal shifts in the $\mathrm{SH}$ and $\mathrm{NH}$ (Figs. 13c,d). This suggests that the EBM does not capture the delayed seasonality of storm track position in the aquaplanet because it does not include dynamical feedbacks.

\section{2) EFFECT OF MIXED LAYER DEPTH ON SURFACE TEMPERATURE}

The EBM mean surface temperature seasonality is small with large mixed layer depth and large with small mixed layer depth consistent with the aquaplanet (Fig. 14). This suggests that one could interpret the mixed layer depth control on storm track seasonality via surface baroclinity. However, the EBM does not quantitatively capture the mean surface temperature seasonality in the aquaplanet. In particular, the temperature in the aquaplanet is delayed relative to the EBM in the limit of small mixed layer depth (Figs. 14c,d). The mean surface temperature delay in the aquaplanet is also consistent with delayed storm track seasonality. Since the thermodynamic component of the mean meridional circulation contribution to storm track intensity is small (Fig. 6c) the results suggest that the storm track feeds back on the mean surface temperature in the aquaplanet, which is not accounted for in the EBM. Thus, the storm track and mean surface temperature are responding to changes in mixed layer depth in the aquaplanet and also influencing each other.

\section{Conclusions and discussion}

\section{a. Conclusions}

Previous work has shown that the observed hemispheric differences in storm track seasonality cannot be explained by insolation alone (B17 and S18). Diagnostic analysis using the MSE framework for zonal-mean storm tracks suggested an important role for differences in surface heat flux (S18). Here we consider the causal role of surface fluxes in determining the intensity and position of the zonal-mean storm tracks. We focus on surface fluxes because 1) they can be controlled by an external parameter (the mixed layer depth) and 2) they affect the seasonality of surface heat fluxes. Assuming the stationary circulation and atmospheric storage do not contribute to storm track seasonality, we hypothesize that surface fluxes modulate storm tracks via two different limits of mixed layer depth:

1) For large mixed layer depth, surface flux is large enough to compensate TOA insolation, net energy input seasonality is small, surface heat fluxes are out of phase with shortwave absorption and storm track seasonality is small.

2) For small mixed layer depth, surface flux is small, net energy input seasonality is large, surface heat fluxes are in phase with shortwave absorption and storm track seasonality is large.

Using a scaling analysis of the MSE budget, we estimate a critical mixed layer depth $\sim 10 \mathrm{~m}$ separates these two limits [see (8)]. The hypotheses are tested by varying the mixed layer depth in zonally symmetric slabocean aquaplanet simulations with zero ocean energy transport. We also examine the impact of varying the mixed layer depth on storm track and mean surface temperature seasonality in an EBM. 
The slab-ocean aquaplanet simulations confirm the large mixed layer depth hypothesis. Namely, for large mixed layer depth the seasonality of net energy input is small, surface heat fluxes are out of phase with shortwave absorption and storm track seasonality is small. The stationary circulation and atmospheric storage contributions are also small. The simulations also confirm some aspects of the small mixed layer depth hypothesis. Namely, for small mixed layer depth the seasonality of net energy input is large, surface heat flux is in phase with shortwave absorption and storm track seasonality is large. However, the hypothesis fails to capture the large contributions from dynamical changes in the Ferrel cell and atmospheric storage.

The slab-ocean aquaplanet simulation with large mixed layer depth captures many aspects of the zonalmean storm track in the $\mathrm{SH}$, that is, small seasonality of net energy input, surface heat fluxes that are out of phase with shortwave absorption, small seasonality of storm track intensity and position and mean surface temperature. Our results are consistent with Donohoe et al. (2014), who showed that a $50 \mathrm{~m}$ mixed layer depth aquaplanet simulation reproduces the seasonality of $\mathrm{SH}$ atmospheric temperature. The addition of an idealized polar ice cap that mimics Antarctica better captures the seasonality of the surface heat flux and OLR contributions to storm track intensity.

The slab-ocean aquaplanet simulation with small mixed layer depth captures some aspects of the zonalmean storm track in the $\mathrm{NH}$, that is, large seasonality of net energy input, surface heat fluxes that are in phase with shortwave absorption and large seasonality of storm track intensity, position and mean surface temperature. However, the detailed evolution is different from the zonal-mean storm track in the NH. In particular, atmospheric storage is much larger in the aquaplanet consistent with the seasonal amplitude of atmospheric temperature increasing with decreasing mixed layer depth (Donohoe et al. 2014). Furthermore, the NH stationary eddies oppose storm track seasonality, consistent with stationary eddies generating downgradient MSE fluxes. Whereas in the aquaplanet with small mixed layer depth, the mean meridional circulation contribution is in phase with storm track intensity consistent with the Ferrel cell generating upgradient MSE fluxes. We show that the mean meridional circulation contribution in the small mixed layer depth simulation arises from dynamical (eddy momentum flux divergence) changes in the Ferrel cell and not from interactions with the Hadley cell.

We focused on the MSE framework for storm tracks because external parameters such as insolation and mixed layer depth do not appear in mean thermodynamic frameworks. Instead we showed that an EBM can be used to understand the impact of mixed layer depth on the seasonality of the storm track and mean surface temperature in the aquaplanet qualitatively. More specifically, the EBM captures the large storm track and mean surface temperature seasonality for small mixed layer depth and small storm track and mean temperature seasonality for large mixed layer depth. However, a detailed comparison with the aquaplanet revealed that the EBM could not quantitatively capture the seasonality in the aquaplanet because it assumes constant annual-mean diffusivity. The diffusivity changes in the aquaplanet are likely related to the interactions between the storm track and mean meridional circulation.

\section{b. Discussion}

Previous work using reanalysis data suggested the hemispheric difference in zonal-mean storm track seasonality is connected to hemispheric differences in mean surface temperature seasonality (O'Gorman 2010). However, mean surface temperature is not an external parameter. Our EBM suggests the underlying reason for the different mean surface temperature seasonality is most likely hemispheric differences in surface heat capacity (mixed layer depth). Furthermore, since the aquaplanet and EBM results show the feedback of the storm track on mean surface temperature is large, one must be cautious when interpreting results using mean surface temperature from reanalysis.

A zonally symmetric aquaplanet with a uniformly small mixed layer depth is clearly not a good idealization of the NH storm track. Donohoe and Battisti (2013) showed that in the NH extratropics, the zonal energy transport by the mean westerly winds damps the seasonal heating over land and amplifies it over ocean. Therefore, a zonal combination of small and large mixed layer depth may better reproduce the $\mathrm{NH}$ storm track. It may also better capture the role of stationary eddies, which generate downgradient MSE fluxes and are important for storm track seasonality in the NH. Quantifying the impact of a zonally dependent mixed layer depth is work in progress.

We show that dynamical changes in the Ferrel cell affect the seasonality of storm tracks in the small mixed layer depth limit. Currently, it is not clear how the Ferrel cell contribution scales with mixed layer depth and whether the small mixed layer depth limit is relevant to past zonally symmetric climates such as Snowball Earth. A better understanding of the Ferrel cell contribution requires a connection between the MSE and momentum budgets. Recent work by Lachmy and Shaw (2018) has made progress in this direction but more work is needed. 
Alternatively, one could transform to potential temperature coordinates to remove the Ferrel cell, but this complicates the surface boundary condition (Held and Schneider 1999).

A limitation of the slab-ocean aquaplanet simulations used in this study is that the mixed layer depth is prescribed and there is no ocean energy transport. The addition of annual-mean ocean energy transport does not change the conclusions (not shown). However, recent observations show that the mixed layer depth in the SH varies seasonally between 30 and $160 \mathrm{~m}$ (see appendix D, Fig. D1; Holte et al. 2017), which is greater than the critical depth $(10 \mathrm{~m})$. Thus, we do not expect the seasonal variations will affect our conclusions. Nevertheless, the impact of mixed layer depth seasonality will be quantified in future work.

Overall, our results show that surface fluxes modulate the seasonal evolution of zonal-mean storm tracks and provide an explanation for the small storm track seasonality in the SH. An assessment of the importance of surface fluxes for the storm track response to forcings on other time scales (increased $\mathrm{CO}_{2}$, Last Glacial Maximum and Snowball Earth) is work in progress.
Acknowledgments. We thank Drs. Ruth Geen and James Penn from the University of Exeter for their support in configuring and running Isca and three anonymous reviewers for their comments. PB and TAS acknowledge support from the National Science Foundation (AGS-1742944). TAS is also supported by the David and Lucile Packard Foundation. The simulations in this paper were completed with resources provided by the University of Chicago Research Computing Center. The model data in this study are available from PB upon request.

\section{APPENDIX A}

\section{Comparison of Storm Track Metrics}

In the MSE framework, storm tracks are defined using a monthly average. Defining the storm track using a monthly average is qualitatively similar to defining them using a 10-day high-pass filter (cf. solid and dashed red lines, Figs. A1 and A2). More specifically, the quasi-stationary (10-30-day filtered) transient eddy contribution is very small (blue lines, Figs. A1 and A2).
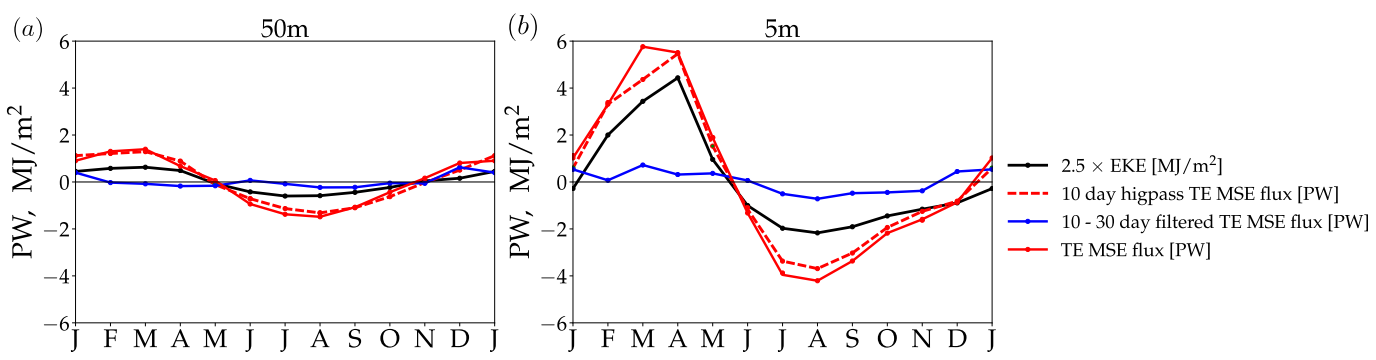

FIG. A1. Seasonal storm track intensity as an anomaly relative to the annual mean defined using vertically integrated transient eddy MSE flux calculated using a monthly average (solid red), 10-day high-pass-filtered MSE flux (dashed red), 10-30-day-filtered MSE flux (blue), and eddy kinetic energy (black). Data are from Isca simulations with (a) 50 and (b) $5 \mathrm{~m}$ slab-ocean mixed layer depth.
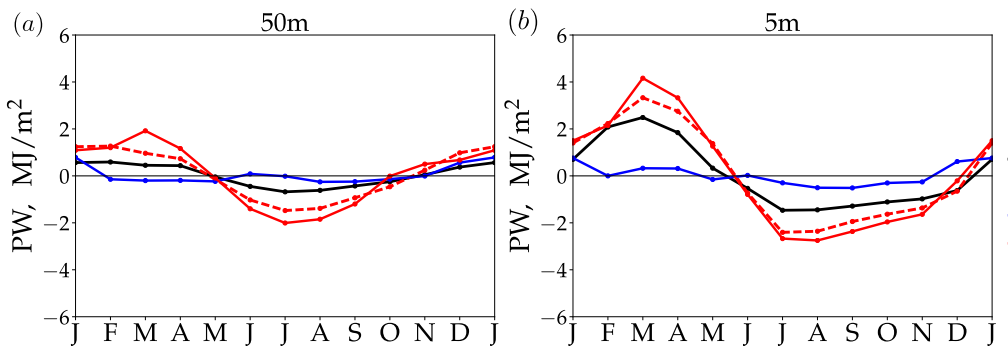

$25 \times \mathrm{EKE}\left[\mathrm{MJ} / \mathrm{m}^{2}\right]$

-... 10 day higpass TE MSE flux [PW] 10 - 30 day filtered TE MSE flux [PW] - TE MSE flux [PW]

FIG. A2. As in Fig. A1, but for GFDL simulations. 


\section{APPENDIX B}

\section{GFDL AM2}

We performed zonally symmetric slab-ocean aquaplanet simulations using GFDL Atmospheric Model 2 (AM2) to corroborate our results from the Isca model (Figs. B1-B11). GFDL AM2 and Isca mostly differ in their convection schemes and the inclusion of cloud radiative effects. The model results are robust for Isca and GFDL, thus the main conclusions are not dependent on convection scheme or the inclusion of cloud radiative effects.
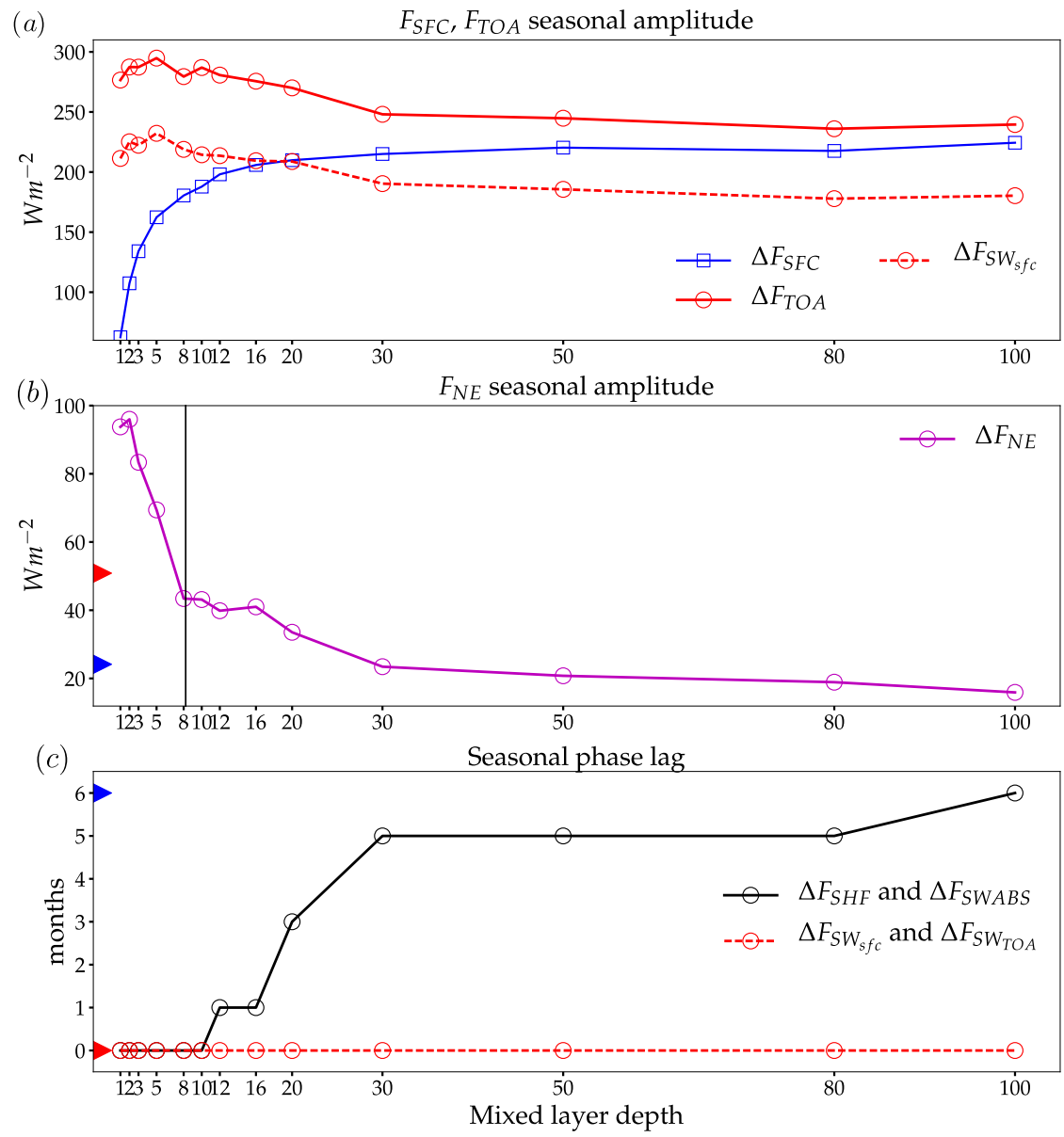

FIG. B1. As in Fig. 2, but for GFDL simulations. 

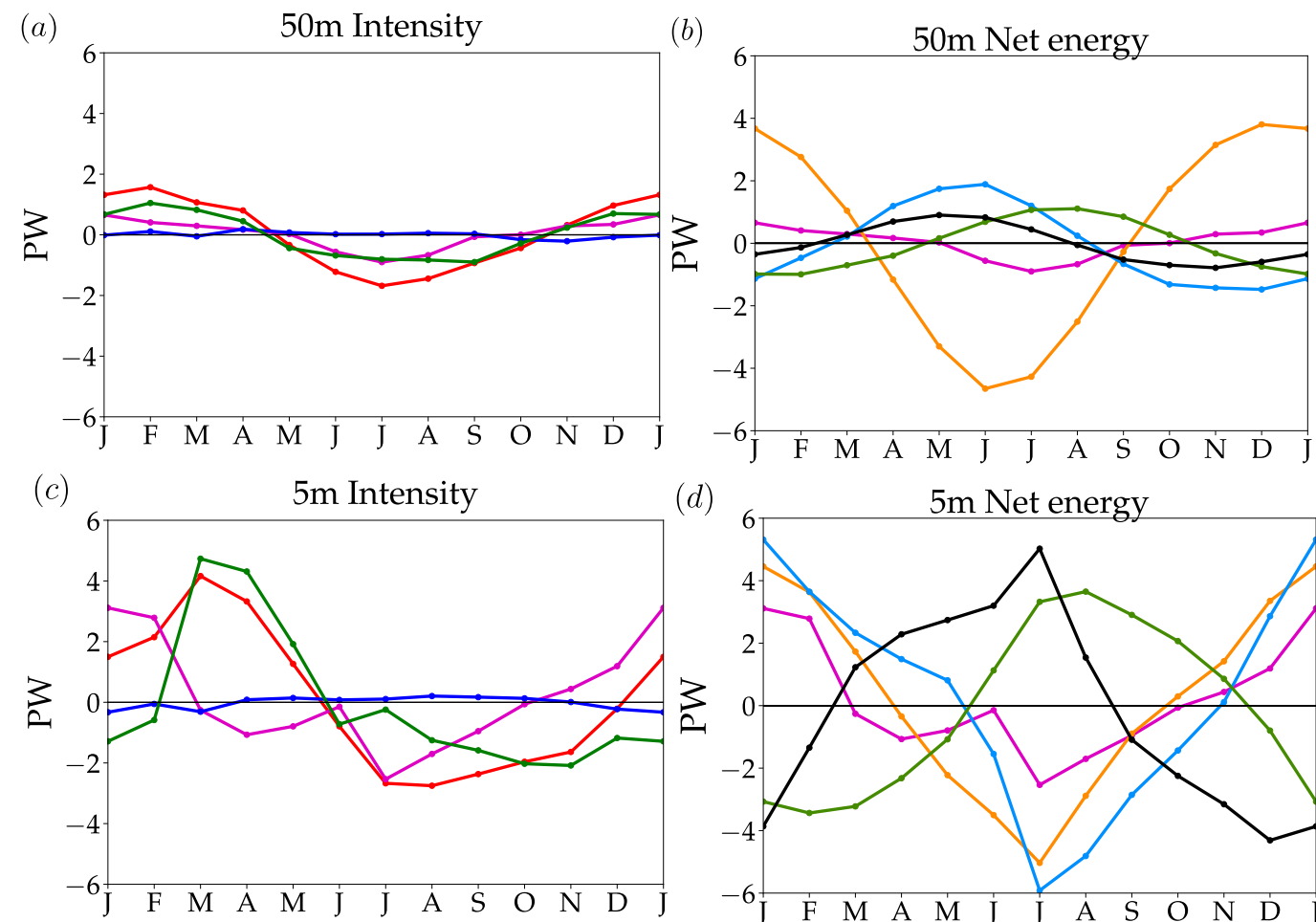

(d)

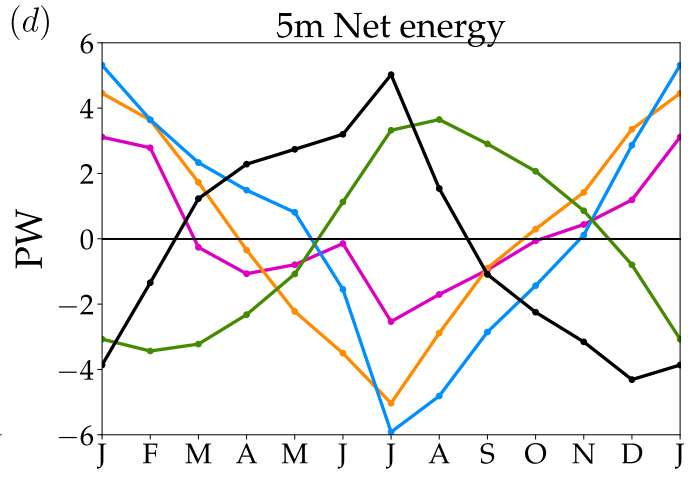

$$
\longrightarrow \Delta I \longrightarrow \Delta I_{N E} \longrightarrow-\Delta I_{S E} \longrightarrow-\Delta I_{M M}
$$

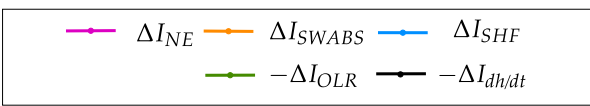

FIG. B2. As in Fig. 3, but for GFDL simulations.
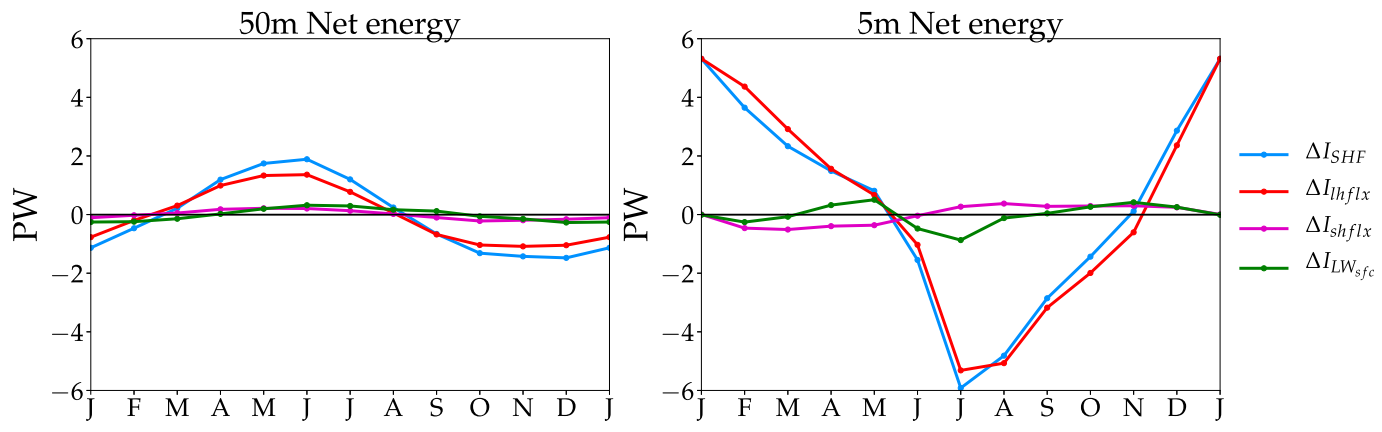

FIG. B3. As in Fig. 4, but for GFDL simulations. 

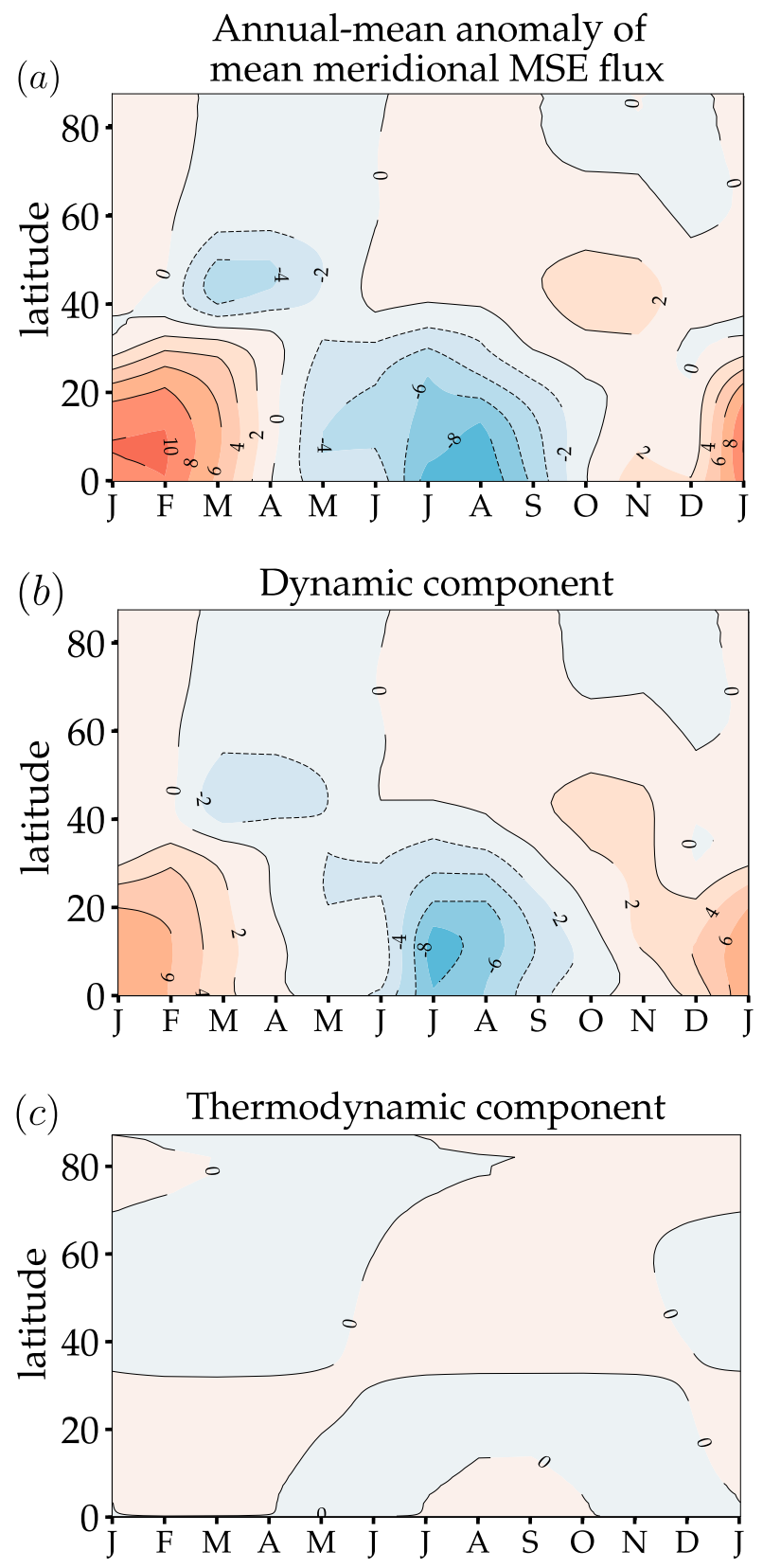

FIG. B4. As in Fig. 6, but for GFDL simulations. 

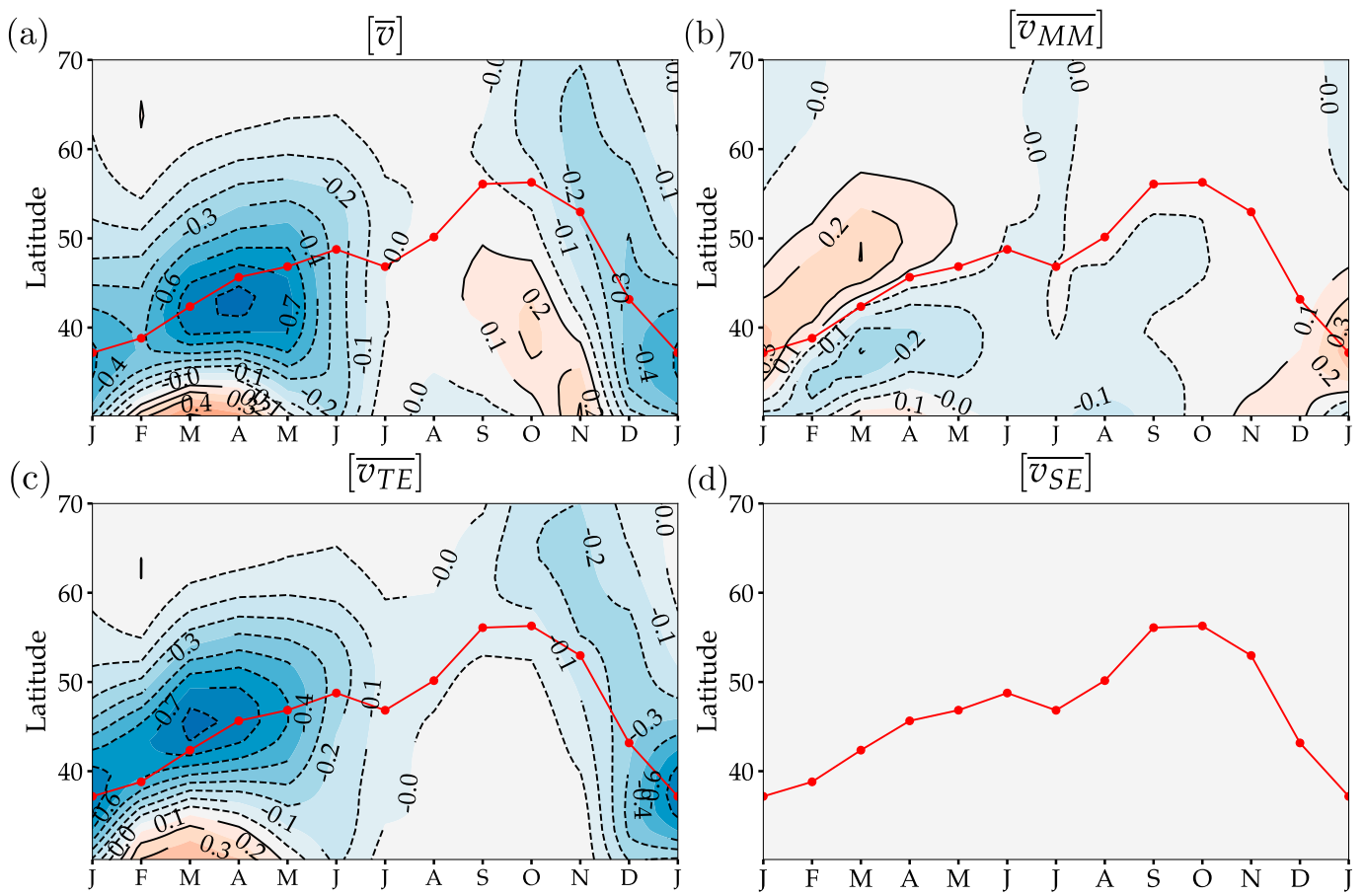

FIG. B5. As in Fig. 7, but for GFDL simulations. 
(a)

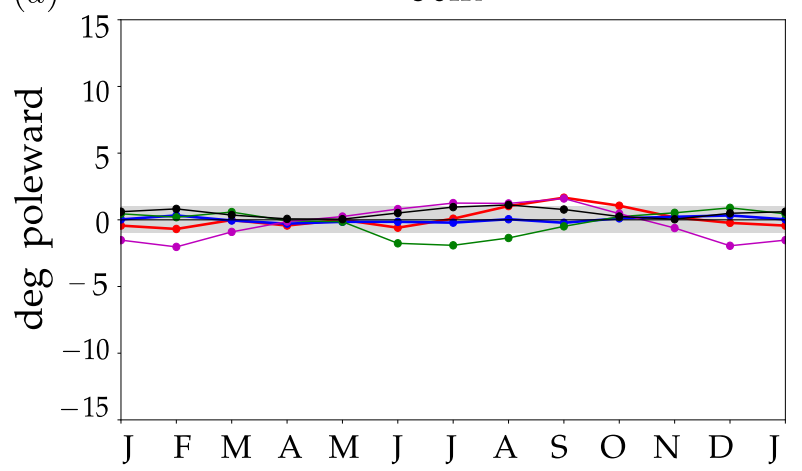

(b)

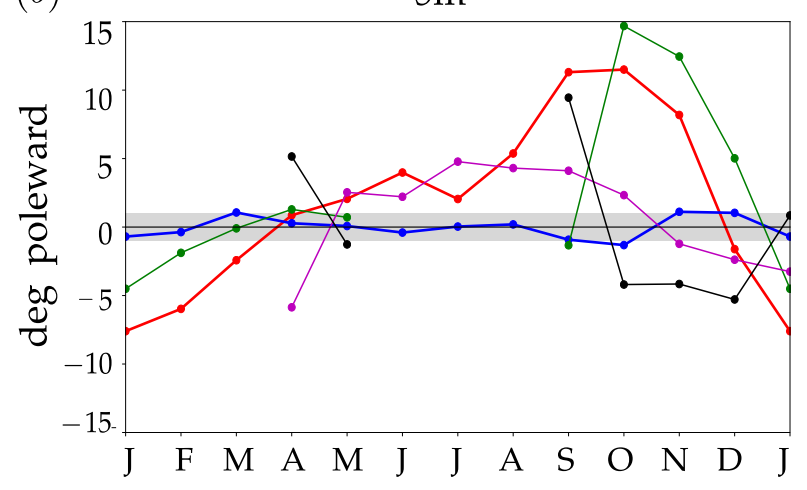

(c) $2 0 \longdiv { 1 0 m - 5 0 m }$

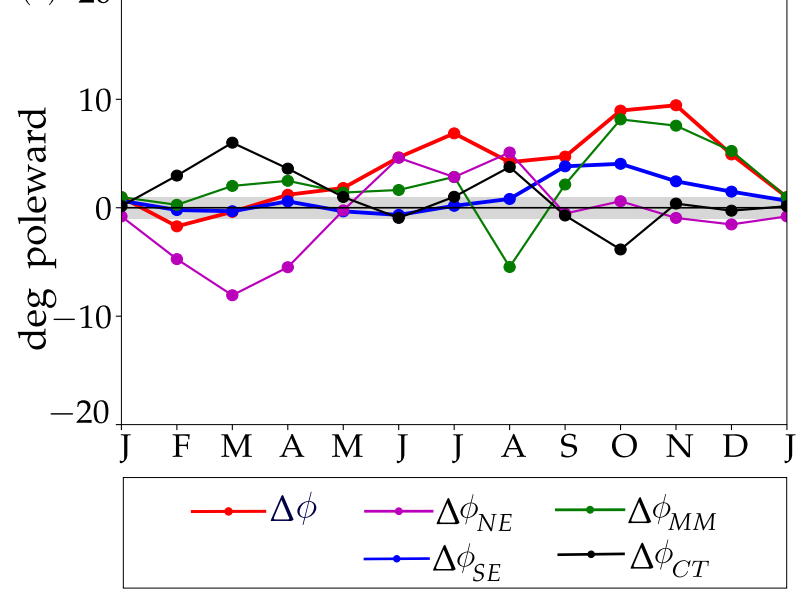

FIG. B6. As in Fig. 8, but for GFDL simulations.

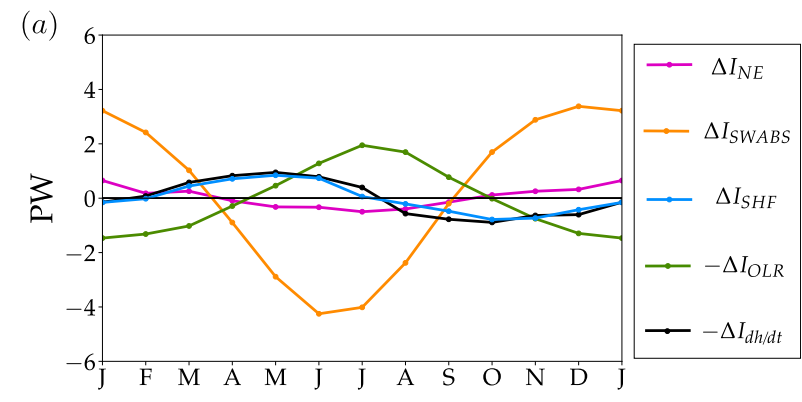

FIG. B7. As in Fig. 9, but for GFDL simulations. 
(a)

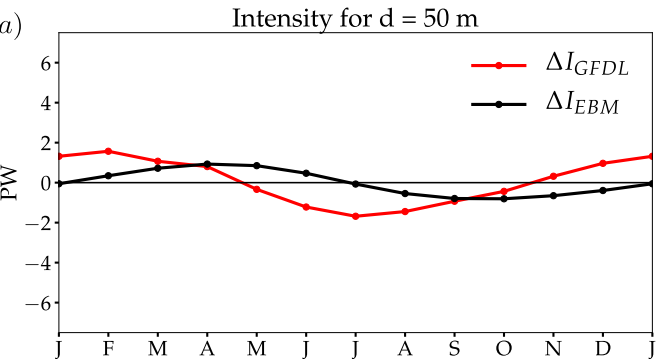

(c)

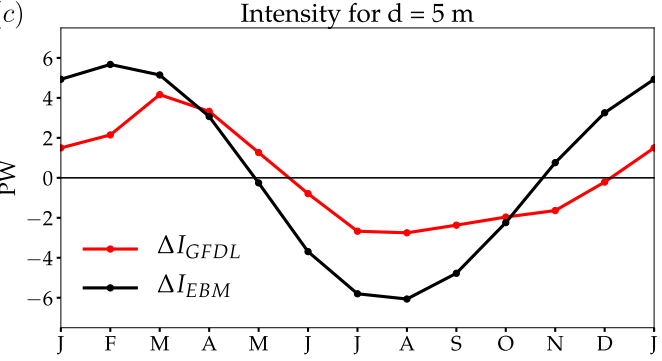

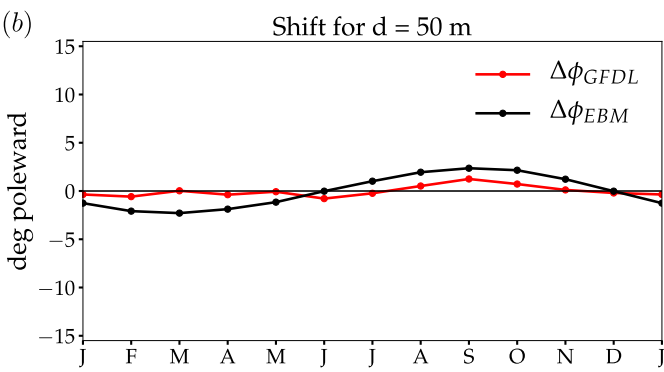

(b)

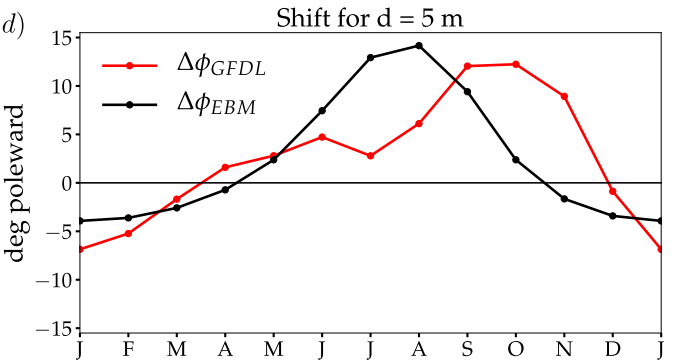

FIG. B8. As in Fig. 10, but for GFDL simulations.
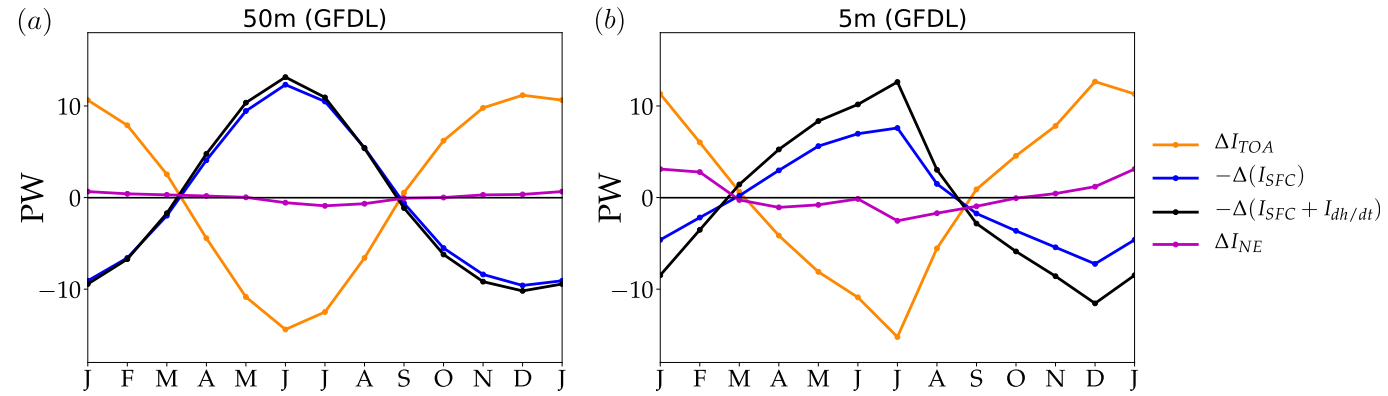

FIG. B9. As in Figs. 11b and 11d, but for GFDL simulations. 

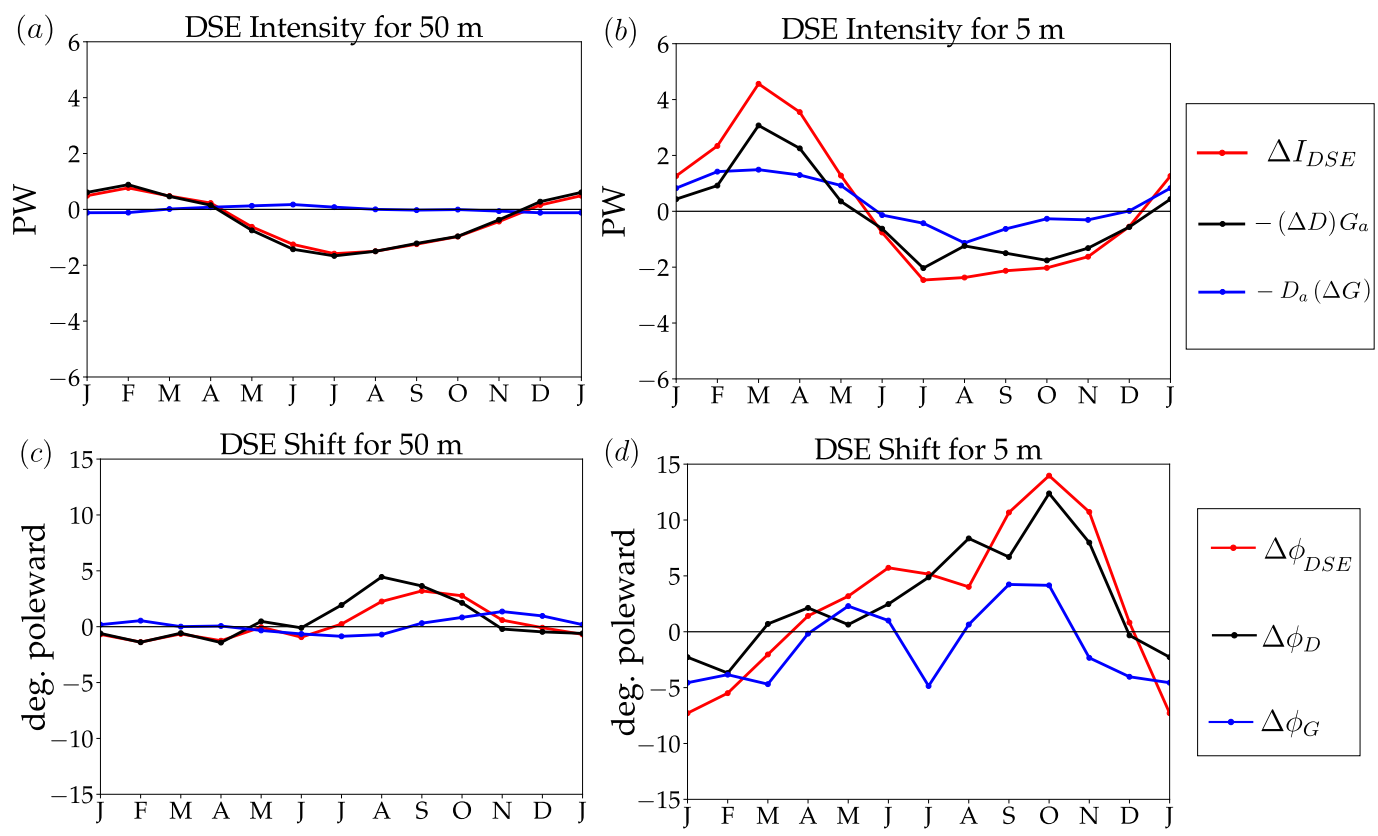

FIG. B10. As in Fig. 12, but for GFDL simulations.

(a)

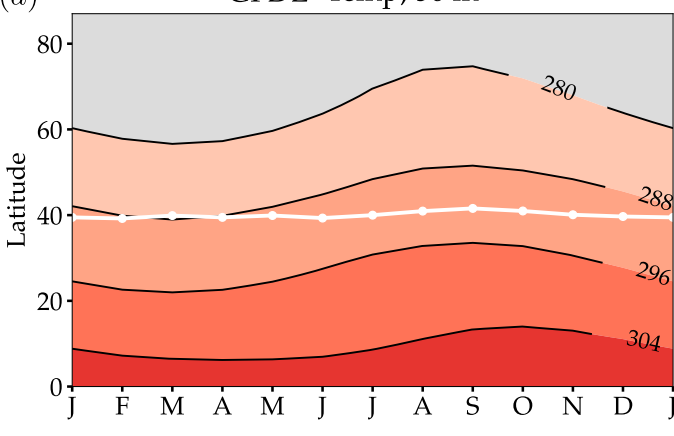

FIG. B11. As in Figs. 13b and 13d, but for GFDL simulations.

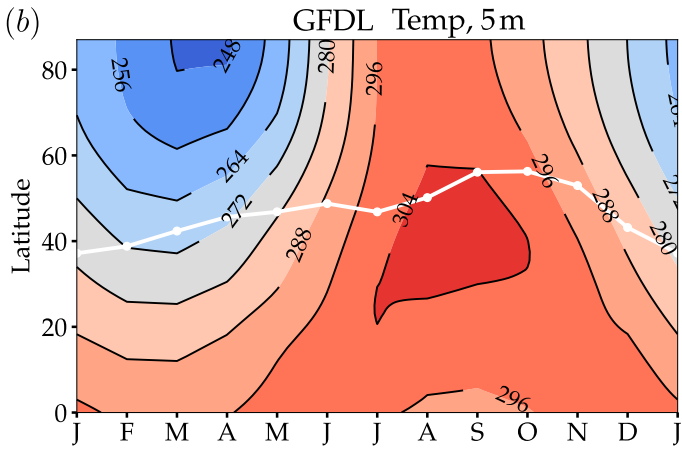




\section{APPENDIX C}

\section{Midwinter Minimum}

We found no midwinter minimum in our zonally symmetric slab-ocean aquaplanet simulations for large and small mixed layer depths for both Isca (Fig. C1) and GFDL (Fig. C2) simulations. In contrast, the zonal-mean storm track exhibits a very clear midwinter minimum in the NH (Fig. 1b). In particular, the storm track is weak when net energy input suggests it should be large (cf. red and magenta lines,
Fig. 1b) because of the compensating behavior of stationary eddies (blue line, Fig. 1b).

Recent studies reported midwinter minimums in zonally symmetric GCMs. For example, Yuval and Kaspi (2018) reported a midwinter minimum when prescribing the vertical temperature structure of the North Pacific sector in a zonally symmetric dry dynamical core. Once again it is difficult to interpret those results because the seasonal-mean temperature-storm track relationship is not causal. Novak et al. (2020) reported a midwinter minimum in slab-ocean aquaplanet simulations with gray radiation with varied
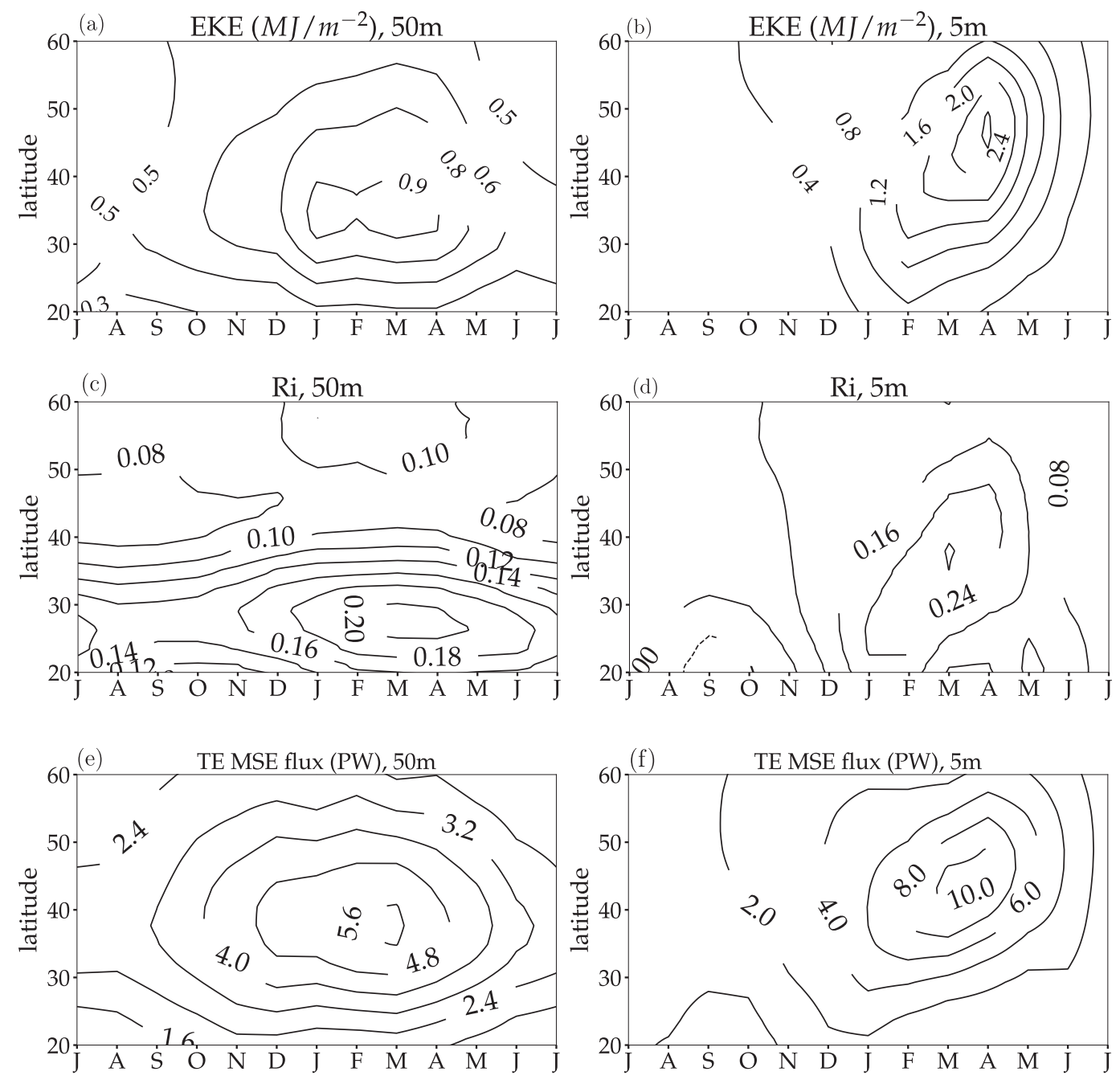

FIG. C1. Seasonal evolution of (a),(b) vertically integrated 10-day high-pass-filtered eddy kinetic energy (EKE), (c),(d) Richardson number as defined in Nakamura (1992), and (e),(f) vertically integrated transient eddy MSE flux. Data are from Isca simulations for (left) 50 and (right) $5 \mathrm{~m}$ slab-ocean mixed layer depth. 

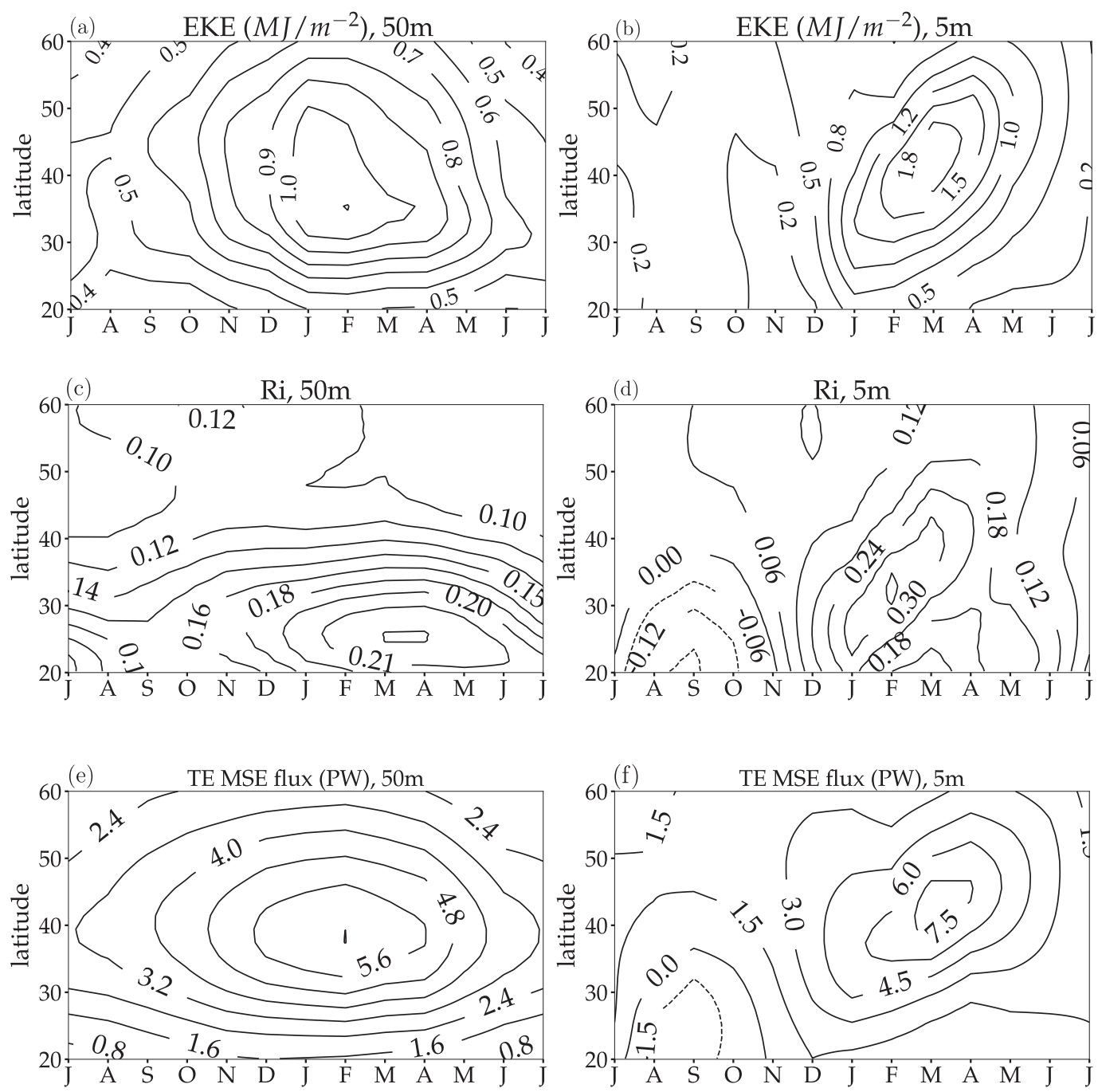

FIG. C2. As in Fig. C1, but for GFDL simulations with (left) 50 and (right) $5 \mathrm{~m}$ slab-ocean mixed layer depth.

ocean energy transport. While their aquaplanet set up is similar to the one used here, we could not reproduce their results with RRTMG or gray radiation.

\section{APPENDIX D}

\section{Seasonal Evolution of SH Mixed Layer Depth}

The SH mixed layer depth based on density profiles from Holte et al. (2017) varies between 30 and $160 \mathrm{~m}$ in the extratropics (Fig. D1). This suggests that the mixed layer depth in the SH exceeds the critical depth of $\sim 10 \mathrm{~m}$ [see (8)] throughout the seasonal cycle.

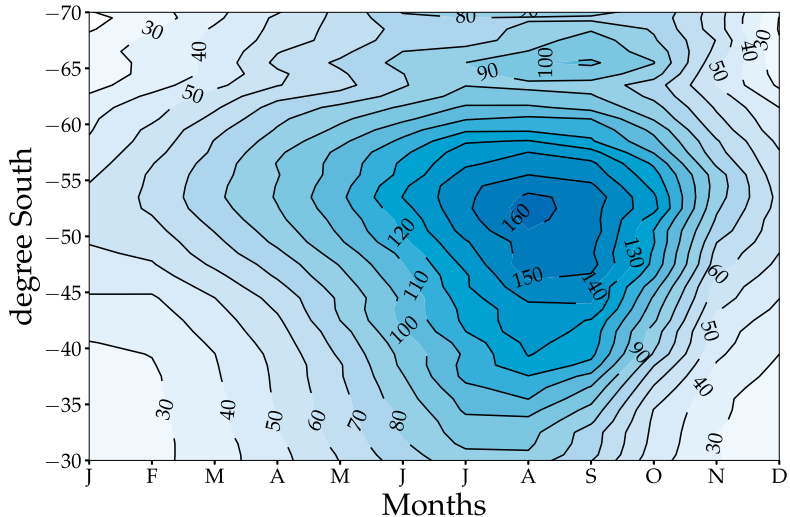

FIG. D1. Seasonal evolution of zonal-mean and monthly mean mixed layer depth in the Southern Hemisphere based on density profiles. Data are obtained from a database of mixed layer properties computed from nearly 1250000 delayed-mode and real-time Argo profiles collected from 2000 to the present (Holte et al. 2017). 


\section{REFERENCES}

Anderson, J. L., and Coauthors, 2004: The new GFDL global atmosphere and land model AM2-LM2: Evaluation with prescribed SST simulations. J. Climate, 17, 4641-4673, https:// doi.org/10.1175/JCLI-3223.1.

Barpanda, P., and T. A. Shaw, 2017: Using the moist static energy budget to understand storm-track shifts across a range of time scales. J. Atmos. Sci., 74, 2427-2446, https://doi.org/10.1175/ JAS-D-17-0022.1.

Betts, A. K., and M. J. Miller, 1993: The Betts-Miller scheme. The Representation of Cumulus Convection in Numerical Models, Springer, 107-121.

Bordoni, S., and T. Schneider, 2008: Monsoons as eddy-mediated regime transitions of the tropical overturning circulation. Nat. Geosci., 1, 515-519, https://doi.org/10.1038/ngeo248.

Ceppi, P., and D. L. Hartmann, 2015: Connections between clouds, radiation, and midlatitude dynamics: A review. Curr. Climate Change Rep., 1, 94-102, https://doi.org/10.1007/s40641-015-0010-x.

Chang, E., S. Lee, and K. K. Swanson, 2002: Storm track dynamics. J. Climate, 15, 2163-2183, https://doi.org/10.1175/1520-0442(2002) 015<02163:STD $>2.0 . \mathrm{CO} ; 2$.

Delworth, T. L., and Coauthors, 2006: GFDL's CM2 global coupled climate models. Part I: Formulation and simulation characteristics. J. Climate, 19, 643-674, https://doi.org/10.1175/JCLI3629.1.

Donohoe, A., and D. S. Battisti, 2013: The seasonal cycle of atmospheric heating and temperature. J. Climate, 26, 4962-4980, https://doi.org/10.1175/JCLI-D-12-00713.1.

, D. M. W. Frierson, and D. S. Battisti, 2014: The effect of ocean mixed layer depth on climate in slab ocean aquaplanet experiments. Climate Dyn., 43, 1041-1055, https://doi.org/10.1007/ s00382-013-1843-4.

Freidenreich, S., and V. Ramaswamy, 1999: A new multiple-band solar radiative parameterization for general circulation models. J. Geophys. Res., 104, 31 389-31 409, https://doi.org/10.1029/1999JD900456.

Geen, R., F. Lambert, and G. Vallis, 2018: Regime change behavior during Asian monsoon onset. J. Climate, 31, 3327-3348, https://doi.org/10.1175/JCLI-D-17-0118.1.

Held, I. M., and T. Schneider, 1999: The surface branch of the zonally averaged mass transport circulation in the troposphere. J. Atmos. Sci., 56, 1688-1697, https://doi.org/10.1175/ 1520-0469(1999)056<1688:TSBOTZ>2.0.CO;2.

— M. Ting, and H. Wang, 2002: Northern winter stationary waves: Theory and modeling. J. Climate, 15, 2125-2144, https://doi.org/ 10.1175/1520-0442(2002)015<2125:NWSWTA > 2.0.CO;2.

Holte, J., L. D. Talley, J. Gilson, and D. Roemmich, 2017: An Argo mixed layer climatology and database. Geophys. Res. Lett., $\mathbf{4 4}$ 5618-5626, https://doi.org/10.1002/2017GL073426.

Hoskins, B. J., and P. J. Valdes, 1990: On the existence of stormtracks. J. Atmos. Sci., 47, 1854-1864, https://doi.org/10.1175/ 1520-0469(1990)047<1854:OTEOST>2.0.CO;2.

Kushner, P. J., and I. M. Held, 1998: A test, using atmospheric data, of a method for estimating oceanic eddy diffusivity. Geophys. Res. Lett., 25, 4213-4216, https://doi.org/10.1029/1998GL900142.

Lachmy, O., and T. A. Shaw, 2018: Connecting the energy and momentum flux response to climate change using the EliassenPalm relation. J. Climate, 31, 7401-7416, https://doi.org/10.1175/ JCLI-D-17-0792.1.

Mbengue, C., and T. Schneider, 2018: Linking Hadley circulation and storm tracks in a conceptual model of the atmospheric energy balance. J. Atmos. Sci., 75, 841-856, https://doi.org/ 10.1175/JAS-D-17-0098.1.
Mlawer, E. J., S. J. Taubman, P. D. Brown, M. J. Iacono, and S. A. Clough, 1997: Radiative transfer for inhomogeneous atmospheres: RRTM, a validated correlated-k model for the longwave. J. Geophys. Res., 102, 16663-16 682, https://doi.org/ 10.1029/97JD00237.

Moorthi, S., and M. J. Suarez, 1992: Relaxed Arakawa-Schubert: A parameterization of moist convection for general circulation models. Mon. Wea. Rev., 120, 978-1002, https://doi.org/10.1175/ 1520-0493(1992)120<0978:RASAPO > 2.0.CO;2.

Nakamura, H., 1992: Midwinter suppression of baroclinic wave activity in the Pacific. J. Atmos. Sci., 49, 1629-1642, https://doi.org/ 10.1175/1520-0469(1992)049<1629:MSOBWA>2.0.CO;2.

Novak, L., T. Schneider, and F. A. Chaalal, 2020: Midwinter suppression of zonally symmetric storm tracks. J. Atmos. Sci., 77, 297-313, https://doi.org/10.1175/JAS-D-18-0353.1.

O'Gorman, P. A., 2010: Understanding the varied response of the extratropical storm tracks to climate change. Proc. Natl. Acad. Sci. USA, 107, 19176-19180, https://doi.org/10.1073/pnas.1011547107. , and T. Schneider, 2008: Energy of midlatitude transient eddies in idealized simulations of changed climates. J. Climate, 21, 5797-5806, https://doi.org/10.1175/2008JCLI2099.1.

Roberts, C. D., M. D. Palmer, R. P. Allan, D. G. Desbruyeres, P. Hyder, C. Liu, and D. Smith, 2017: Surface flux and ocean heat transport convergence contributions to seasonal and interannual variations of ocean heat content. J. Geophys. Res. Oceans, 122, 726-744, https://doi.org/10.1002/2016JC012278.

Rose, B. E., 2018: Climlab: A Python toolkit for interactive, process oriented climate modeling. J. Open Source Software, 3, 659, https://doi.org/10.21105/joss.00659.

Schneider, T., 2006: The general circulation of the atmosphere. Annu. Rev. Earth Planet. Sci., 34, 655-688, https://doi.org/ 10.1146/annurev.earth.34.031405.125144.

— the seasonal cycle of a Hadley circulation and implications for monsoon dynamics. J. Atmos. Sci., 65, 915-934, https://doi.org/ 10.1175/2007JAS2415.1.

Seager, R., N. Harnik, Y. Kushnir, W. Robinson, and J. Miller, 2003: Mechanisms of hemispherically symmetric climate variability. J. Climate, 16, 2960-2978, https://doi.org/10.1175/ 1520-0442(2003)016<2960:MOHSCV>2.0.CO;2.

— N. Naik, and G. A. Vecchi, 2010: Thermodynamic and dynamic mechanisms for large-scale changes in the hydrological cycle in response to global warming. J. Climate, 23, 4651-4668, https://doi.org/10.1175/2010JCLI3655.1.

Shaw, T. A., and Coauthors, 2016: Storm track processes and the opposing influences of climate change. Nat. Geosci., 9, 656664, https://doi.org/10.1038/ngeo2783.

— , P. Barpanda, and A. Donohoe, 2018: A moist static energy framework for zonal-mean storm-track intensity. J. Atmos. Sci., 75, 1979-1994, https://doi.org/10.1175/JAS-D-17-0183.1.

Vallis, G. K., 2006: Atmospheric and Oceanic Fluid Dynamics: Fundamentals and Large-Scale Circulation. Cambridge University Press, 745 pp., https://doi.org/10.1017/CBO9780511790447.

- and Coauthors, 2018: Isca, v1. 0: A framework for the global modelling of the atmospheres of Earth and other planets at varying levels of complexity. Geosci. Model Dev., 11, 843-859, https://doi.org/10.5194/gmd-11-843-2018.

Yuval, J., and Y. Kaspi, 2018: The relation between the seasonal changes in jet characteristics and the Pacific midwinter minimum in eddy activity. Geophys. Res. Lett., 45, 9995-10 002, https://doi.org/10.1029/2018GL078678. 